\title{
Application of Hexagonal Fuzzy MCDM Methodology for Site Selection of Electric Vehicle Charging Station
}

\author{
Arijit Ghosh ${ }^{1}{ }^{\oplus}$, Neha Ghorui ${ }^{2}$, Sankar Prasad Mondal ${ }^{3, *}$, Suchitra Kumari ${ }^{4}$, Biraj Kanti Mondal ${ }^{5}$, \\ Aditya Das ${ }^{6}$ and Mahananda Sen Gupta ${ }^{4}$ \\ 1 Department of Mathematics, St. Xavier's College (Autonomous), Kolkata 700016, India; \\ arijitghosh@sxccal.edu \\ 2 Department of Mathematics, Prasanta Chandra Mahalanobis Mahavidyalaya, Kolkata 700108, India; \\ neha.mundhra@thebges.edu.in \\ 3 Department of Applied Science, Maulana Abul Kalam Azad University of Technology, West Bengal, \\ Haringhata 741249, India \\ 4 Department of Commerce, St. Xavier's College (Autonomous), Kolkata 700016, India; \\ suchitra@sxccal.edu (S.K.); mahanandasg@gmail.com (M.S.G.) \\ 5 Department of Geography, Netaji Subhas Open University, Kolkata 700016, India; \\ birajmondal.kolkata@gmail.com \\ 6 Department of Commerce, University of Calcutta, Kolkata 700073, India; dasaditya635@gmail.com \\ * Correspondence: sankarprasad.mondal@makautwb.ac.in; Tel.: +91-96-3557-8078
}

Citation: Ghosh, A.; Ghorui, N.; Mondal, S.P.; Kumari, S.; Mondal, B.K.; Das, A.; Gupta, M.S. Application of Hexagonal Fuzzy MCDM Methodology for Site Selection of Electric Vehicle Charging Station. Mathematics 2021, 9, 393

https://doi.org/10.3390/math9040393

Academic Editor: Michael Voskoglou

Received: 28 December 2020

Accepted: 9 February 2021

Published: 16 February 2021

Publisher's Note: MDPI stays neutral with regard to jurisdictional claims in published maps and institutional affiliations.

Copyright: (c) 2021 by the authors. Licensee MDPI, Basel, Switzerland. This article is an open access article distributed under the terms and conditions of the Creative Commons Attribution (CC BY) license (https:/ / creativecommons.org/licenses/by/ $4.0 /)$.

\begin{abstract}
In this paper, the application of hexagonal fuzzy multiple-criteria decision-making (MCDM) methodology for the site selection of electric vehicle charging stations is considered. In this regard, four factors and thirteen sub-factors have been taken into consideration for E-vehicle charging site selection. In this research, the geographic information system (GIS) has been incorporated with MCDM techniques. The fuzzy analytic hierarchy process (FAHP) is used to obtain a fuzzy weight of factors and sub-factors. MCDM tools fuzzy technique for order of preference by similarity to ideal solution (FTOPSIS) and fuzzy complex proportional assessment (FCOPRAS) have been used to rank the selected sites. A centroid-based method for defuzzification and distance measure between two hexagonal fuzzy numbers (HFN) has been developed for this paper. A practical example in Howrah, India, is considered to show the applicability and usefulness of the model. The results depict the suitability of the proposed research. Comparative and sensitivity analyses have been demonstrated to check the reliability, robustness and effectiveness of the proposed method.
\end{abstract}

Keywords: site selection; FAHP; FTOPSIS; FCOPRAS; hexagonal fuzzy number

\section{Introduction}

Electric vehicles play a very momentous role in addressing fossil fuel pollution and they are capable of making a paradigm shift in the entire transportation sector. Transportation is a significant contributor to urban air pollution and the reduction of urban city emission is the need of the hour. Electric vehicles make the world more liveable and provide a pollution-free mode of transportation in urban areas. The high level of pollution is degrading the environment and it has made the concept of sustainable development a fairy-tale phenomenon [1,2]. Sustainable consumption needs to be adopted by conducting timely environmental and sustainability assessments to prevent any large-scale ecological disaster from happening. This is where electrical vehicles come into the picture, with sustainability, environment-protecting and pocket-friendly being a few of their rewards. Electric vehicles use a minimum of one electric motor or traction motor for propulsion. They maybe self-contained with a generator or battery for converting the fuel into electricity or they may be power-drivenvia a collector scheme by using electricity from off-vehicle sources [3]. The problem of the energy crisis in the world can be tackled in the future by using this option. Ever-rising gas prices force people to look for alternative modes of 
energy supply, or to even switch over to walking or availing public transportation. The other reason why electrical vehicles are preferred over fossil-fueled vehicles is due to their eco-friendly nature and the cheaper cost of driving them [4,5]. Filling up an electric car costs less than filling up a full tank. Internal combustion engines emit more $\mathrm{CO}_{2}$ emissions than electric vehicles [6-8].

Moreover, for the promotion of charging stations, we need to focus on two facets: the power of the government and the role of the market. The government influences taxation policies and subsidy policies directly on the stations, thus affecting the income of the charging station. On the other hand, from the market viewpoint, the key is the demand and supply relationship, i.e., the consumers who demand the electric vehicles and the supply of electric vehicle charging and the electric vehicle charging stations [9].Electric vehicles can usually be charged in three ways i.e., by using inductive charging, conductive charging and the battery replacement method [7]. The inductive method of charging works through an electromagnetic transmission keeping no contact between the charging station and the electric vehicle. The conductive method has a battery connected by a cable which is directly plugged into an electricity provider, whereas the battery replacement method replaces the discharged batteries with new batteries in a charging station, keeping in mind the internal connections and the dimensions of the batteries, resulting in it being the least used method. The charging station operators mostly use conductive charging since it is more efficient and cheaper [10].The benefits of electric vehicles outweigh the problems. They are energy efficient since they convert a higher rate of electrical energy from the grid to power, compared to gasoline vehicles. They do not make noise or pollute the air since the electric motors have a quiet and smooth operation, requiring low maintenance. Their use of electricity reduces the need for fossil fuels [11]. The major problem with electric vehicles is their shorter driving range. The time taken to recharge the vehicle is also usually long and the battery packs are heavy and expensive [12]. Establishing an economic, efficient and convenient electric vehicle charging station will speed up the purchase of electric vehicles for consumers, thereby developing the sector and it viceversa will hinder electric vehicle adoption leading to lesser incentives for investing in its development [13]. Selecting a suitable site for electric vehicle charging stations is of utmost importance since it has a direct linkage to the operation efficiency and the service quality of the charging stations throughout its entire life cycle [14-16]. Electric vehicle charging station (EVCS) site selection requires a comprehensive analysis of social, economic, environmental, operations and urban planning for which several prospective and potential alternative locations were considered with respect to a range of criteria. Hence, location selection is seen as a multiple-criteria decision-making (MCDM) problem. The technique for order of preference by similarity to ideal solution (TOPSIS) is an aggregation of the MCDM method, having the benefits of computational efficiency and the ability to measure in simple mathematical form the relative performance of each alternative criterion [17-23]. However, due to information deficiency and vagueness along with human qualitative judgements, some criteria fail to be measured by a crisp value and can only be a fuzzy value [24] such as the development planning of road networks and petrol stations. Fuzzy theory effectively tackles this issue [25].In today's times, finding a suitable EVCS site requires a multi-criteria approach as well as accuracy and reliability in the maps [26]. The efficacy of the final decision depends on the quality of the data which are used to produce criteria maps. The geographic information system-based multi-criteria decision analysis (GIS-based MCDA) method converts spatial as well as non-spatial data into information with respect to the decision-maker's own judgement [27]. To promote e-vehicle usage, longterm infrastructure installation is the need of the hour. For long-term infrastructure creation, detailed study of the criteria and in-depth analysis is required. This paper addresses the problem of charging infrastructure creation for e-vehicles in a city environment. This model can be replicated in different cities for a pollution-free mode of transport. Widespread usage of e-vehicles will make the environment greener. 


\subsection{Literature Review}

The construction of an electric vehicle charging station is the turning point in its life cycle. Selecting an appropriate place for setting up the charging station and determining its capacity will benefit all the stakeholders and endorse sustainable development of the entire industry. Some studies have been shown this with respect to economy and technology. Lee et al. [28] examined the price competition among EVCSs using renewable power generators by employing game theory with relevant physical constraints. Rivera et al. [29] put forward a novel architecture for plug-in electric vehicles: a DC charging station using a grid-tied neutral point clamped converter. Wang et al. [30] utilized threephase uncontrolled rectification chargers to study the harmonic amplification of EVCSs. Ding, Hu and Song [31] studied the energy storage system as a potential supplement of an electric bus fast charging station by employing mixed integer nonlinear programming for valuing the energy storage system. Fan, Sainbayar and Ren [32] calculated the effect of limiting electric vehicles' full state of charge to total charged energy and the revenue of EVCS. Capasso and Veneri [33] built a DC fast charging architecture for plug-in hybrid vehicles as well as fully electric vehicles by integrating the fleets of hybrid/road electric vehicles with renewable energy sources. Li et al. [34] studied the control of EVCSs and the management of energy and fit them in a dynamic price framework by developing a realtime simulation system for evaluating how the EVCS meets the charging and discharging requirements for grid-to-vehicle, vehicle-to-grid and vehicle-to-vehicle. Nansai et al. [35] conducted the life-cycle analysis on EVCSs in three phases of installation, transportation and production of electric vehicle charging equipment and then compared the carbon dioxide, carbon monoxide, sulphur oxides and nitrogen oxide emissions of electric vehicles and gasoline vehicles.

Research also focuses on the electric vehicle's size, its placement and the fields in which it is used. Khalkhali et al. [36] determined the optimal location and size of plug-in hybrid EVCSs using data envelopment analysis by maximizing the benefit of the distribution system management. Frade et al. [15] studied the location of EVCSs in Portugal by employing a maximal covering model for defining the capacity and number of EVCSs. Liu [37] investigated the nascent electric vehicle market in Beijing and then formulated an assignment model for different charging infrastructure assignment strategies. Wirges, Linder and Kessler [38] predicted several scenarios for charging infrastructure development until 2020 in Germany and also formulated a dynamic spatial model for the allocation of the EVCSs in the country. Wang et al. [39] developed an EVCS location model considering the electricity consumed along the roads and the oil sales, after which the EVCS quantity and layout were calculated. He et al. [40] developed an equilibrium modeling framework for deciding the optimal allocation of the charging stations in a metropolitan area. Liu et al. [41] proposed a two-step screening method for determining the optimal EVCS site, taking environmental factors and service radius into consideration.

There have been a large number of researches which have employed a type of decisionmaking method. Pashajavid and Golkar [42] put forward a scenario optimization algorithm by using multivariate stochastic modeling methodology for load demand by allocating the charging station of plug-in electric vehicles and also used a particle swarm optimization algorithm to minimize voltage deviation and energy loss in the distribution system. Chen, Kockelman and Khan [43] determined the optimal charging station location assignment in Seattle by developing a mixed-integer programming model which minimized the station access cost of the electric vehicle users and took trip attributes, parking demand, population density and local job as constraints. Sathaye and Kelley [44] used a continuous facility location model considering the demand uncertainty for finding the optimal location of the public-funded electric vehicle infrastructure on the highway corridors. Wang et al. [45] determined the optimal size and location of EVCSs with respect to smart grids by proposing a multi-objective EVCS planning method, maximizing the electric vehicle traffic flow under the constraint of battery capacity and the final optimal solution data-envelopment analysis was obtained and employed. Dong, Liu and Lin [46] 
formulated an activity-based assessment method for the evaluation of the feasibility of electric vehicles taking the heterogeneous travelling population and subsequently applying a genetic algorithm for determining the sub optimal location. $\mathrm{Xu}$ et al. [47] identified the candidate centralized charging station using a proposed mathematical model with the minimum total transportation distance. You and Hsieh [48] used the mixed-integer programming model to determinine the best location of the EVCS which would maximize the number of people who could complete round-trip itineraries, along with developing an efficient hybrid genetic algorithm which would obtain a compromised solution in a reasonable time. Lee et al. [49] first collected users' charging and traveling behaviors along with the batteries' state of charge and then proposed a location model of the rapid EVCS by using a probabilistic distribution function for the remaining fuel range. Baouche et al. [50] formulated an integer linear optimization model, taking the electric vehicle's input consumption as the optimal model. Sadeghi-Barzani [16] postulated a mixed-integer non-linear optimization approach for the determination of the optimal size and place of fast charging stations. Yao et al. [51] devised a multi-objective collaborative planning strategy to tackle the planning issue in electric vehicle charging systems and integrated power distributions by using a decomposition-based multi-objective evolutionary algorithm model and equilibrium-based traffic assignment model. Ma et al. [52] used an agent-based model to optimize the sketch of the initial EVCS. Chung and Kwon [53] devised a multi-period optimization model to perform the EVCS planning, basing it on the real traffic flow data of the Korean Expressway network in 2011. Lam, Leung and Chu [54] used four solution methods i.e., the greedy approach, chemical reaction optimization, iterative mixed-integer linear programming and effective mixed-integer linear programming for the EVCS place problem by checking them against practical and artificial cases. Cai et al. [55] found the relation between public charging infrastructure development and the travel patterns mined from big-data taken using large-scale trajectory data in Beijing.

Multi-criteria decision-making was used in transhipment site selection [56], shopping mall site selection [57], railway station site selection [58], waste management site selection [59] and macro-site selection of solar/wind hybrid power station [60].

The major drawback of the aforementioned studies which use multi-criteria decisionmaking approaches is the lack of incorporation between evaluation criteria and spatial data, since selecting a suitable site for an EVCS is a spatial decision predicament which involves conflicting, incommensurate and multiple evaluation criteria and a large set of evaluation criteria. Two unique parts of research i.e., multi-criteria decision-making and GIS can aid each other to overcome the intersections between evaluation criteria and spatial data. GIS integrates the spatially-referenced data in a problem-solving environment whereas multi-criteria decision-making refers to procedures and techniques used in structural decision problems by evaluating, prioritizing and designing the alternative decisions [61]. GIS-based multi-criteria decision-making techniques are usually used for spatial decision problems such as freight village site selection [62] wind power plant site selection [63] and refugee camp site selection [64]. Even though there have been multiple studies on the GIS-based multi-criteria decision-making approach on spatial decision problems as mentioned above, still there is a gap in the selection of EVCS sites using GIS.

\subsection{Objectives of the Study}

The present research has the following objectives:

(a) Identification of the most preferred site for the construction of an e-vehicle charging station.

(b) Application of hexagonal fuzzy numbers (HFN) in AHP-TOPSIS and AHP-COPRAS to obtain the ranking of the selected sites.

\subsection{Novelties of the Study}

Several researchers have explored fuzzy numbers with MCDM techniques AHP, TOPSIS, and COPRAS. Hardly any research has been done using hexagonal fuzzy numbers 
under MCDM methodology. The HFN defuzzification formulae has been developed and utilized. Distance measured between two HFN is also defined. The formulae has been developed to calculate the hexagonal fuzzy weight of factors and sub-factors. A technique has been developed to incorporate more than one decision maker's opinion into a single comprehensive value in terms of HFN. Two different ranking methods, fuzzy AHP-TOPSIS and fuzzy AHP-COPRAS has been used in this research. GIS software has been used for distance measurement and graphical presentation of the selected sites.

\subsection{Structure of the Paper}

The remainder of the paper is organized in the following way: Section 2 depicts the concept of fuzzy numbers, HFN, its properties, distance measure, and defuzzification formulae. It also includes the MCDM technique AHP, fuzzy TOPSIS and fuzzy COPRAS. Section 3 contains the numerical application and description of factors and sub-factors. Section 4 represents the comparison and sensitivity analysis, respectively. The results and discussion covered in Sections 5 and 6 describes the future scope and conclusion.

The structured framework of the study represented in Figure 1 describes the sequential steps followed in this paper. After the initial selection of factors and sub-factors, their weights are calculated by AHP and FAHP. Subsequently, FTOPSIS and FCOPRAS MCDM tools have been applied for the selection of preferred locations followed by comparative and sensitivity analysis, overall results and discussions.

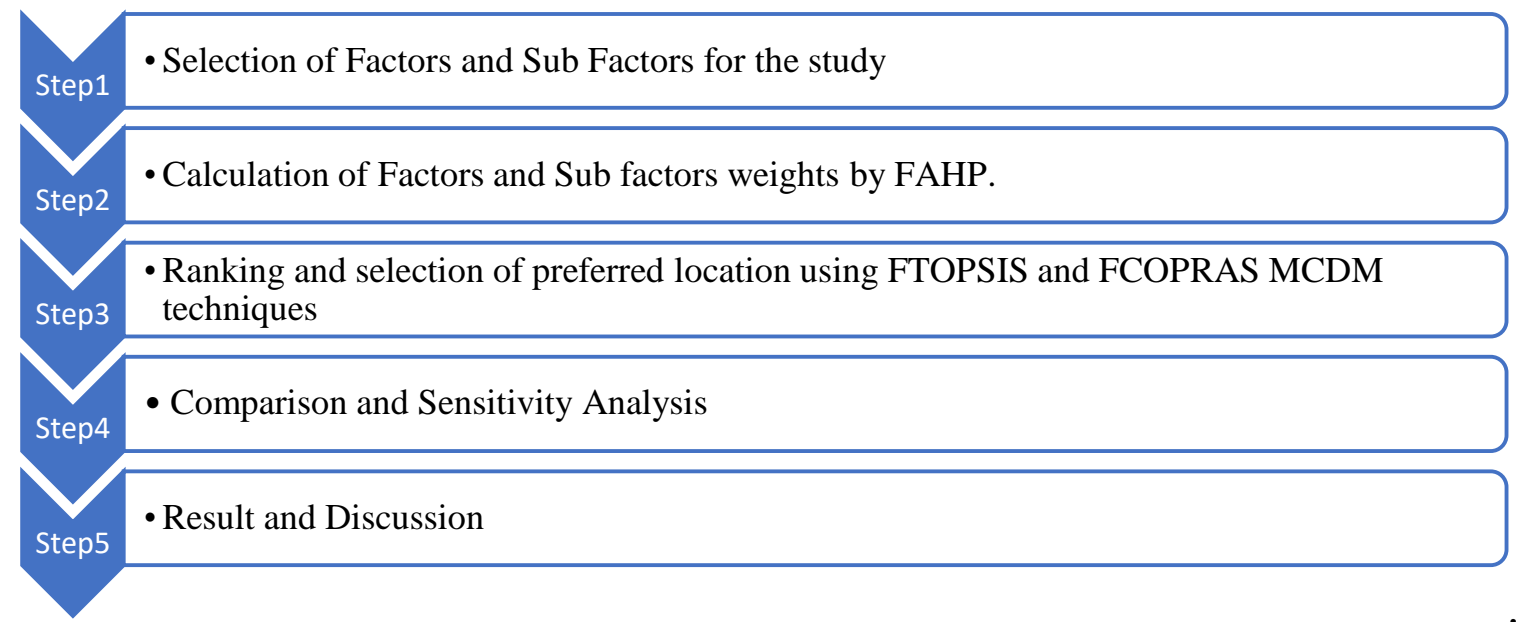

Figure 1. Structural framework of the study. FTOPSIS: fuzzy technique for order of preference by similarity to ideal solution; FCOPRAS: fuzzy complex proportional assessment; MCDM: multiple-criteria decision-making.

\section{Preliminaries}

\subsection{Fuzzy Set}

The fuzzy set theory was developed by the author [25] to deal with the impreciseness of real-life issues [65-73].

Definition 1. A set $\hat{T}$, defined as $\hat{T}=\left\{\left(\tau, \mu_{\hat{T}}(\tau): \tau \in \hat{T}, \mu_{\hat{T}}(\tau) \in(0,1)\right\}\right.$, where $\mu_{\hat{T}}(\tau)$ represents the membership function of $\hat{T}$ which takes value from zero to one. In real life situations, where the information is vague and uncertain, fuzzy logic can be efficiently used to deal with these problems.

Definition 2. Hexagonal fuzzy number (HFN) A number $\alpha_{H F N}=\left\{\left(h_{1}, h_{2}, h_{3}, h_{4}, h_{5}, h_{6}\right), \mu_{\alpha}(x)\right\}$ is defined as HFN if it satisfies the following properties:

a. $\quad \mu_{\alpha}(x)$ is a continuous function [0, 1].

b. $\quad \mu_{\alpha}(x)$ is strictly increasing continuous function in $\left[h_{1}, h_{2}\right]$ and $\left[h_{2}, h_{3}\right]$. 
c. $\quad \mu_{\alpha}(x)$ attains maximum value 1 in $\left[h_{3}, h_{4}\right]$.

d. $\quad \mu_{\alpha}(x)$ is strictly decreasing continuous function in $\left[h_{4}, h_{5}\right]$ and $\left[h_{4}, h_{5}\right]$.

The following Figure 2 represents the membership function of symmetric HFN.

$$
\mu_{\alpha}(x)=\left\{\begin{array}{cc}
0, & \text { for } \mid x \leq h_{1} \\
\frac{0.5\left(x-h_{1}\right)}{h_{2}-h_{1}}, & \text { for } h_{1} \leq x \leq h_{2} \\
0.5+\frac{0.5\left(x-h_{2}\right)}{h_{3}-h_{2}}, & \text { for } h_{2} \leq x \leq h_{3} \\
1, & \text { for } h_{3} \leq x \leq h_{4} \\
1-\frac{0.5\left(x-h_{4}\right)}{h_{5}-h_{4}}, & \text { for } h_{4} \leq x \leq h_{5} \\
0.5-\frac{0.5\left(x-h_{5}\right)}{h_{6}-h_{5}}, & \text { for } h_{5} \leq x \leq h_{6} \\
0, & \text { for } x \geq h_{6}
\end{array}\right.
$$

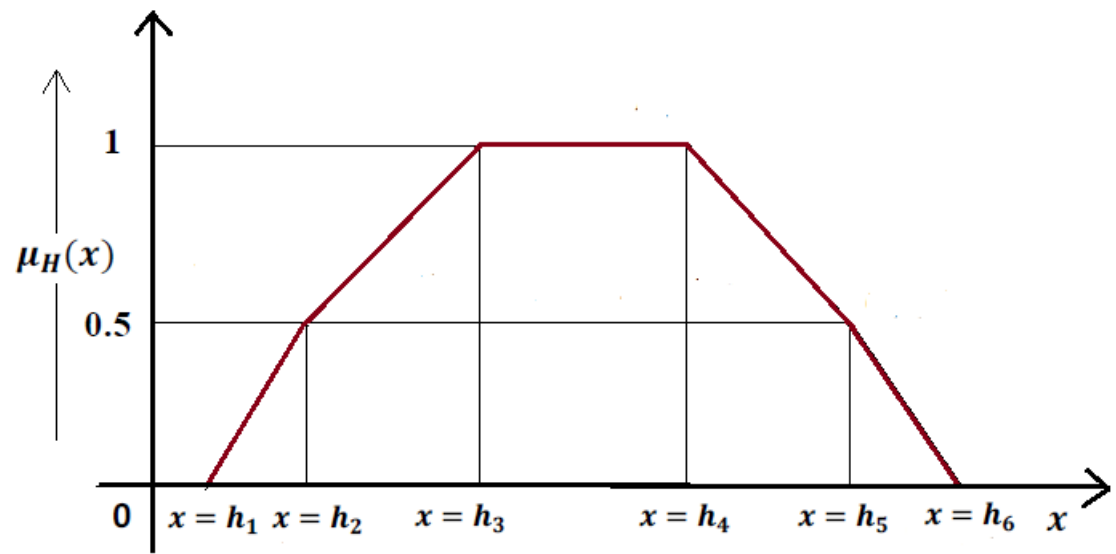

(a)

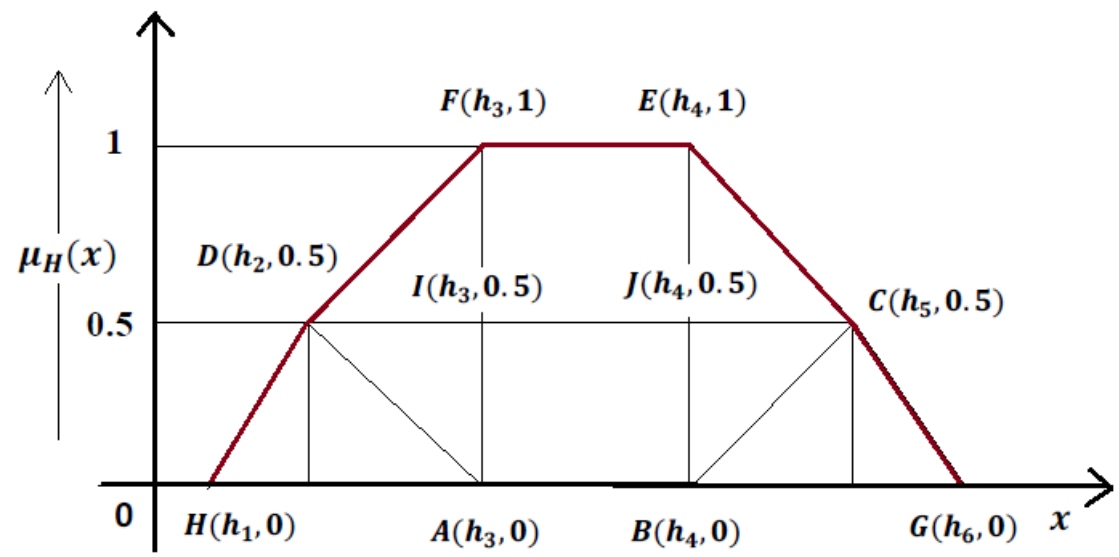

(b)

Figure 2. (a) Representation of the membership function of linear hexagonal fuzzy number (HFN). (b) Hexagonal fuzzy number as union of different regions.

Where $h_{1}, h_{2}, h_{3}, h_{4}, h_{5}$ and $h_{6}$ are real numbers such that $h_{1} \leq h_{2} \leq h_{3} \leq h_{4} \leq h_{5} \leq h_{6}$.

Note 2.1: Hexagonal fuzzy numbers (HFN) capture the hesitancy and uncertainty in broader aspects compared to triangular fuzzy numbers (TFN), trapezoidal fuzzy numbers (TrFN), and pentagonal fuzzy numbers (PFN) as the latter undertakes three, four, and five numbers, respectively, to represent the impreciseness and ambiguity of the decision maker (DM). If we consider the linguistic term corresponding to TFN then it is represented 
numerically as (low, medium, high) where the medium value corresponds to the best possible chances of the quantity. For TrFN, the numerical presentation is expressed as (very low, low, high, very high) and the maximum possibility lies in a range of (low, high). Further, if we take PFN, it considers the numerical behavior as (very low, low, medium, high, very high), here the middle value denotes the maximum possibility, which is 1 . HFN undertakes the highest level of distribution in the numerical form as (very very low, very low, low, high, very high, very very high), i.e., the maximum possible spread can be accommodated in HFN. With respect to a developing country in an unplanned city, many of the attributes under consideration have a wider range of linguistic representation which cannot be captured using TFN, TrFN and PFN. For example, the consumption level in a city with a heterogeneous earning pattern can be better captured using HFN with a wider range. The hesitancy of decision makers in such an environment requires a broader range of values to depict uncertainty; HFN enables this.

The hesitancy of decision makers (DMs) can be better captured in HFN. Different levels of hesitancy in linguistic terms corresponding to different HFN. It is easy to understand and analyze that the linguistic terms "weakly important" represented in HFN as (1.1, 1.2, $1.3,1.4,1.5,1.6)$, "absolutely important" represented in HFN as $(4.6,4.8,5,5.2,5.4,5.7)$ and so on. These range from lower values of HFN to higher values. Similarly, the inverse of these HFN, specifically, the opposites of the linguistic terms can be obtained by using Equation (7).

\subsection{Arithmetic Operations of Linear Symmetric HFN}

Let $U=\left(u_{1}, u_{2}, u_{3}, u_{4}, u_{5}, u_{6}\right)$ and $V=\left(v_{1}, v_{2}, v_{3}, v_{4}, v_{5}, v_{6}\right)$ be two HFN, then their general arithmetic operations can be defined in the following way:

1. Addition:

$$
(U+V)=\left(u_{1}+v_{1}, u_{2}+v_{2}, u_{3}+v_{3}, u_{4}+v_{4}, u_{5}+v_{5}, u_{6}+v_{6}\right)
$$

2. Subtraction:

$$
(U-V)=\left(u_{1}-v_{6}, u_{2}-v_{5}, u_{3}-v_{4}, u_{4}-v_{3}, u_{5}-v_{2}, u_{6}-v_{1}\right)
$$

3. Multiplication:

$$
(U \times V)=\left(u_{1} v_{1}, u_{2} v_{2}, u_{3} v_{3}, u_{4} v_{4}, u_{5} v_{5}, u_{6} v_{6}\right)
$$

4. Scalar Multiplication:

$$
\alpha U=\left(\alpha u_{1}, \alpha u_{2}, \alpha u_{3}, \alpha u_{4}, \alpha u_{5}, \alpha u_{6}\right)
$$

5. Division:

$$
\left(\frac{U}{V}\right)=\left(\frac{u_{1}}{v_{6}}, \frac{u_{2}}{v_{5}}, \frac{u_{3}}{v_{4}}, \frac{u_{4}}{v_{3}}, \frac{u_{5}}{v_{2}}, \frac{u_{6}}{v_{1}}\right)
$$

6. Inverse:

$$
U^{-}=\left(\frac{1}{u_{6}}, \frac{1}{u_{5}}, \frac{1}{u_{4}}, \frac{1}{u_{3}}, \frac{1}{u_{2}}, \frac{1}{u_{1}}\right)
$$

\subsection{Distance Measure of Two HFN}

Definition 3. Let $\widetilde{A_{d}}=\left(a_{1}, a_{2}, a_{3}, a_{4}, a_{5}, a_{6}\right)$ and $\widetilde{B_{d}}=\left(b_{1}, b_{2}, b_{3}, b_{4}, b_{5}, b_{6}\right)$ be two HFNs, then the distance between the two HFNs can be determined as: 


$$
\begin{aligned}
& d\left(\widetilde{A_{d}}, \widetilde{B_{d}}\right)= \\
& \sqrt{1 / 6\left[\left(a_{1}-b_{1}\right)^{2}+\left(a_{2}-b_{2}\right)^{2}+\left(a_{3}-b_{3}\right)^{2}+\left(a_{4}-b_{4}\right)^{2}+\left(a_{5}-b_{5}\right)^{2}+\left(a_{6}-b_{6}\right)^{2}\right]}
\end{aligned}
$$

Example 1. Let $U=(1.2,1.3,1.5,1.6,1.8,2)$ and $V=(1,1.3,1.7,2,2.1,2.3)$ be two HFNs then, their distance

$$
\begin{aligned}
& d(U, V) \\
& =\sqrt{1 / 6\left[(1.2-1)^{2}+(1.3-1.3)^{2}+(1.5-1.7)^{2}+(1.6-2)^{2}+(1.8-2.1)^{2}+(2-2.3)^{2}\right]} \\
& =0.26
\end{aligned}
$$

\subsection{Centroid-Based Method for the Defuzzification of Hexagonal Fuzzy Numbers}

A HFN can be considered as the union of two triangles and two trapeziums, e.g., $\triangle \mathrm{ADH}, \triangle \mathrm{BCG}, \mathrm{ABCD}$ and $\mathrm{CDEF}$ together form a HFN.

Further, the trapezium is a union of two triangles and one rectangle. Applying a centroid-based method to triangles and rectangles, and finally summing them, we obtain the centroid of the HFN. Since, the defuzzified value should remain within the range of a HFN, the formulae given below provides the required defuzzified value. Derivation of the HFN is executed in the following way:

(i). Centroid of

$$
\triangle B C G=\left(\frac{h_{4}+h_{5}+h_{6}}{3}, \frac{0.5}{3}\right)
$$

(ii). Centroid of

$$
\triangle A D H=\left(\frac{h_{1}+h_{2}+h_{3}}{3}, \frac{0.5}{3}\right)
$$

(iii). Centroid of Trapezium $A B C D$ :

(a) Centroid of

$$
\Delta A D I=\left(\frac{h_{2}+2 h_{3}}{3}, \frac{1}{3}\right)
$$

(b) Centroid of

$$
\triangle B C D=\left(\frac{2 h_{4}+h_{5}}{3}, \frac{1}{3}\right)
$$

(c) Centroid of Rectangle

$$
\begin{gathered}
A B I J=\left(\frac{h_{3}+h_{4}}{2}, \frac{0.5}{2}\right) \\
C_{A B C D}\left(\frac{2 h_{2}+7 h_{3}+7 h_{4}+2 h_{5}}{18}, \frac{11}{2}\right)
\end{gathered}
$$

(iv). Centroid of Trapezium CDEF is calculated in the similar order and we obtain:

$$
C_{C D E F}=\left(\frac{2 h_{2}+7 h_{3}+7 h_{4}+2 h_{5}}{18}, \frac{25}{12}\right)
$$

The defuzzified value is determined by summing Equations (9), (10), (14) and (15) and dividing the denominator by the sum of the quantities of the numerator.

$$
C_{H G C E F D}=\left(\frac{3 h_{1}+3 h_{2}+10 h_{3}+10 h_{4}+5 h_{5}+3 h_{6}}{34}, \frac{10}{3}\right)
$$


Example 2. Let $U=(1.5,1.6,1.7,1.9,2,2.1)$, then the defuzzified value of

$$
U=\frac{4.5+4.8+17+19+10+6.3}{34}=1.8
$$

\subsection{Determination of Hexagonal Fuzzy Weights of Factors and Sub-Factors}

We have extended the methodology developed by Buckley [74] for TFNs in the context of determining hexagonal fuzzy weight.

Step 1. The geometric mean value of the HFN is obtained using:

$$
k_{c}=\left(\prod_{d=1}^{j} y_{c d}\right), c=1,2, \ldots, i
$$

Step 2. Summation of each $k_{c}$

Step 3. To calculate the inverse of each $k_{c}$ and arrange it in increasing order.

Step 4. To find the hexagonal fuzzy weight of factors and sub-factors using the following equation:

$$
w_{c}=k_{c} *\left(k_{1}+k_{2}+\ldots+k_{i}\right)^{-1}
$$

Step 5. The global hexagonal fuzzy weight of sub-factors are computed by the product of factor weight with the respective sub-factor fuzzy weight.

\subsection{Fuzzy Analytic Hierarchy Process (FAHP)}

The AHP was introduced by Satty [75]. It is used widely for the evaluation of factor and sub-factor weights. AHP helps in solving the real-life situations with a scientific approach. The comparison of factors and sub-factors, thereby giving preference in linguistic terms can be considered as a hesitant task for DMs, thus HFN with AHP methodology captures the vagueness of the problem. The determination of factors' and sub-factors' weights are important for ranking the electric vehicle charging station. AHP works with a problem hierarchy where a comparison matrix is constructed to represent subjective judgments regarding criteria and sub-criteria. In this work, FAHP is taken instead of AHP, keeping in mind the fuzzy setting represents the uncertainties of the decision experts. The FAHP concept with fuzzy logic allows the DMs in the evaluation of reliable results. The steps of FAHP are given below.

Step 1. Construction of a comparison matrix in terms of HFN by a group of decision experts.

Let a group of ' $H$ ' decision-makers assigned for the comparison of factors and subfactors. Let each DM express their preference in the pairwise comparison of factors and sub-factors. Thus, ' $h$ ' set of matrices are obtained, $T_{h}=\left\{t_{c d h}\right\}$.

Where $t_{c d h}=\left(\widetilde{m}_{c d h}, \widetilde{n}_{c d h}, \widetilde{o}_{c d h}, \widetilde{p}_{c d h}, \widetilde{q}_{c d h}\right)$ denotes the HFN of $c$ factor to $d$ factor as expressed by the ' $h$ ' DM.

$$
\left\{\begin{aligned}
\widetilde{m}_{c d} & =\min _{h=1,2, \ldots, H} \widetilde{m}_{c d h} \\
\widetilde{n}_{c d} & =\min _{h=1,2, \ldots, H} \widetilde{n}_{c d h} \\
\widetilde{o}_{c d} & =\sqrt[H]{\prod_{h=1}^{H} \widetilde{o}_{c d h}} \\
\widetilde{p}_{c d} & =\sqrt[H]{\prod_{h=1}^{H} \widetilde{p}_{c d h}} \\
\widetilde{q}_{c d} & =\max _{h=1,2, \ldots, H} \widetilde{q}_{c d h} \\
\widetilde{r}_{c d} & =\max _{h=1,2, \ldots, H} \widetilde{r}_{c d h}
\end{aligned}\right.
$$

Step 2. Defuzzification of HFN: 
A HFN can be defuzzified by using the centroid-based method used in this paper. Thus using Equation (16), the HFN is transformed to a crisp value.

Step 3. Normalization of the defuzzified matrix:

$$
N_{c d}=\frac{M_{c d}}{\sum_{c=1}^{i} M_{c d}} \text {, where } c=1,2, \ldots, i ; d=1,2, \ldots, j ;
$$

Step 4. Estimation of factors' and sub-factors' weights:

$$
E=\frac{N^{\text {th }} \text { rootvalue }}{\sum N^{\text {th }} \text { root }}
$$

Step 5. To test the Consistence Index (C.I) of the matrix:

$$
(C . I)=\frac{\alpha_{\max }-j}{j-1}
$$

where $j$ denotes the size of the matrix.

Step 6. Determination of Consistence Ratio (C.R):

$$
C . R=\frac{C . I}{R . I}
$$

where R.I is stand for Random Index, and its value differs with the size of the matrix " $n$ ".

The assessment of $C . R \leq 0.1$ is acceptable and indicates that the weights obtained are justified. Thus further evaluation is not essential.

\subsection{Technique for Order Preference by Similarity to Ideal Solution (TOPSIS) and (FTOPSIS)}

The TOPSIS MCDM tool is an extensively used technique, developed by Hwang and Yoon [76] to rank the alternatives, thus giving an idea as to which choice is most preferred. The TOPSIS method is considered to be a distance measure method in which the optimal alternative obtained is farthest away from the negative ideal solution (NIS) and nearest to the positive ideal solution (PIS). The linguistic human decisions can be reflected suitably with Fuzzy TOPSIS (FTOPSIS). The approach is useful in handling the complexity of the situation involving several factors and their sub-factors. In this research, for the selection of the best site to construct an electric vehicle charging station, it is dependent on multiple conflicting factors and sub-factors, thus the MCDM method FTOPSIS introduced by Sodhi and Prabhakar [77] is one of the most helpful and reliable methods. The fuzzy logic extends our goal to obtain more sensitive results in this regard. The steps of FTOPSIS are described below.

Step 1: Construction of the decision matrix by the help of decision experts in terms of linguistic terms. The linguistic terms are then converted to a HFN.

Step 2: To evaluate the normalized HFN fuzzy decision matrix:

$$
\begin{gathered}
\check{N D}=\left[n_{g h}\right]_{s t}, g=1,2, \ldots, s ; h=1,2, \ldots \ldots, t \\
N_{g h}=\left(\frac{a_{1 g h}}{a^{*}}, \frac{a_{2 g h}}{a^{*}}, \frac{a_{g h h}}{a_{*}^{*}}, \frac{a_{4 g h}}{a_{*}^{*}}, \frac{a_{5 g h}}{a_{*}^{*}}, \frac{a_{6 g h}}{a_{*}^{*}}\right) d \in B . A, a_{6}^{*}=\max a_{g h} \\
N_{g h}=\left(\frac{a_{h}^{*}}{a_{6 g h}}, \frac{a_{h}^{*}}{a_{5 g h}}, \frac{a_{h}^{*}}{a_{4 g h}}, \frac{a_{h}^{*}}{a_{3 g h}}, \frac{a_{h}^{*}}{a_{2 g h}}, \frac{a_{h}^{*}}{a_{1 g h}}\right) d \in \text { N.B.A, } a_{h}^{*}=\min a_{1 g h}
\end{gathered}
$$

where B.A and N.B.A signifies the benefit attributes and non-benefit attributes, respectively. Step 3: To evaluate the weighted fuzzy normalized matrix, the sub-factors' fuzzy weights are multiplied with the normalized fuzzy value:

$$
W N=\left[P_{g h}\right]_{s t} g=1,2, \ldots, s ; h=1,2, \ldots, t
$$


where

$$
P_{g h}=N_{g h} \times \hat{W}_{h}, g=1,2, \ldots, s ; h=1,2, \ldots, t
$$

Step 4: Calculate the fuzzy positive ideal solution (FPIS) $\left(\right.$ PIS $\left.^{+}\right)$and fuzzy negative ideal solution (FNIS) $\left(N I S^{-}\right)$, where $h_{g}^{+}$denotes the maximum value of $h_{g h}$ and $h_{g}^{-}$denotes the minimum value of $h_{g h}$ :

$$
\left.\left.\begin{array}{l}
\text { PIS }^{+}=\left\{a_{1}^{+}, a_{2}^{+}, \ldots, a_{t}^{+}\right\}=\left\{\begin{array}{l}
\left(\max a_{g h} \mid h \in M_{B}\right),\left(\min a_{g h} \mid h \in M_{N B}\right) \\
N I S^{-}=\left\{a_{1}^{-}, a_{2}^{-}, \ldots, a_{t}^{-}\right.
\end{array}\right\}=\left\{\left(\min _{g h} \mid h \in M_{B}\right),\left(\operatorname{maxh}_{g h} \mid h \in M_{N B}\right)\right.
\end{array}\right\}\right\}
$$

where $M_{B}$ denotes the benefit attributes and $M_{N B}$ denotes the non-benefit attributes.

Step 5: Calculation of the distance measure of all alternatives from the PIS and NIS. The two Euclidean distances for individual alternatives can be calculated as follows:

$$
\left.\begin{array}{rl}
L_{g}^{+} & =\sum_{h=1}^{t} \mathrm{~d}\left(P_{g h}, h_{g}^{+}\right), g=1,2, \ldots \ldots s . \\
L_{g}^{-} & =\sum_{h=1}^{t} \mathrm{~d}\left(P_{g h}, h_{g}^{-}\right), g=1,2, \ldots \ldots, s .
\end{array}\right\}
$$

where $\mathrm{d}(.$, . $)$ denotes the Euclidean distance between two fuzzy numbers. Step 6: Determination of the relative closeness to the ideal alternatives:

$$
R_{g}=\frac{L_{g}^{-}}{L_{g}^{-}+L_{g}^{+}}, g=1,2, \ldots, s
$$

Step 7: Rank the alternatives:

The alternatives are ranked based on the score obtained by $R_{g}$. The larger value of $R_{g}$ signifies the better alternatives.

\subsection{Fuzzy COPRAS Methodology}

The complex proportional assessment (COPRAS) method was first introduced by Zavadskas, Kaklauskas and Sarka [78]. Fuzzy COPRAS is an extended approach of the COPRAS technique, widely used for decision-making problems. It uses the stepwise ranking and evaluation procedure for the alternatives with reference to significance and utility degree. A few applications of the COPRAS method are in economics, construction and property management. An extension of the COPRAS method is Fuzzy COPRAS, which is frequently used in decision-making problems. Ghose et al. [79] used a hybrid fuzzy COPRAS method for selecting the optimal material to be used for a solar car. They took into consideration 19 materials which had 14 different properties. Using a sensitivity analysis, the robustness of the model was checked. The reason for using the fuzzy-based MCDM technique was that it helps decision makers to get over the problems of ambiguous data. Tolga and Durak [80] used the fuzzy COPRAS technique in the air cargo sector for evaluating the potential capability. 18 criteria were chosen for selecting the best out of the present six alternatives. The steps of the COPRAS method are illustrated below:

Step 1. Decision matrix is constructed in terms of HFN, the alternatives are given linguistic terms by the decision experts with respect to the criteria.

Step 2. Normalized decision matrix is formulated using Equation (1), in the similar way, we constructed for TOPSIS normalized matrix.

Step 3. Weighted normalized matrix is constructed by multiplying the criteria weights with fuzzy normalized matrix using Equation (19).

Step 4. Aggregation of beneficial $B_{g}^{+}$and non-beneficial indices $N B_{g}^{-}$for each alternative are evaluated.

$$
B_{g}^{+}=\left\{\sum_{h=1}^{m} N W^{a_{1}}, \sum_{h=1}^{m} N W^{a_{2}}, \sum_{h=1}^{m} N W^{a_{3}}, \sum_{h=1}^{m} N W^{a_{4}}, \sum_{h=1}^{m} N W^{a_{5}}, \sum_{h=1}^{m} N W^{a_{6}}\right\}
$$




$$
N B_{g}^{-}=\left\{\sum_{h=m+1}^{t} N W^{a_{1}}, \sum_{h=m+1}^{t} N W^{a_{2}}, \sum_{h=m+1}^{t} N W^{a_{3}}, \sum_{h=m+1}^{t} N W^{a_{4}}, \sum_{h=m+1}^{t} N W^{a_{5}}, \sum_{h=m+1}^{t} N W^{a_{6}}\right\}
$$

where $h=1,2, \ldots, \mathrm{m}$ represents the benefit attribute of the alternatives and $h=m+$ $1, m+2, \ldots, t$ represents the non-benefit attributes of the alternative.

Step 5. Finally, the aggregated beneficial and non-beneficial indices are defuzzified using the Equation (9) and $R_{+g}$ and $R_{-g}$ are determined.

Step 6. Calculation of $R_{g}$ using the following formulae:

$$
R_{g}=R_{+g}+\frac{R_{-\min } \sum_{g=1}^{l} R_{-g}}{R_{-g} \sum_{g=1}^{l} \frac{R_{-\min }}{R_{-g}}}
$$

Step 7. Ranking of the alternatives are done using the formulae:

$$
R=\frac{R_{g}}{R_{\max }} * 100 \%
$$

where $R_{g}$ represents the g-thdefuzzified value and $R_{\max }$ represents the maximum defuzzified value of individual alternative.

\section{Hexagonal Fuzzy MCDM Methodology for Site Selection of Electric Vehicle Charging Station (Numerical Application)}

3.1. The Factors and Sub Factors Taken in This Research Have Been Explained in the Following Way 3.1.1. Economic Factors $\left(C_{1}\right)$

The prosperity of a nation is comprehended by the state of its economy. The assessment of the economic factors reveals the feasibility of the undertaken study. The factors considered are:

- Land cost $\left(C_{11}\right)$ : It is the crux of the entire planning for the optimum charging station location. Land costs are based on their use, i.e., non-agricultural urban land is more costly than agricultural land. Since the purpose is to build a charging station, we can minimize the land cost by utilizing an already existing utility station. If money is saved on the cost of procuring the land, then it can be utilized for setting up the station.

- $\quad$ Operating and management cost $(\mathrm{OMC})\left(\mathrm{C}_{12}\right)$ : Yao, Bai and $\mathrm{Xu}$ [81] stated that a significant part of the budgeted amount is cut out for dealing with operating and management costs which arise in the day to day working of the project. The minimum management cost is essential since it helps in the smooth flow of the information from one department to the other. The charging station should be executed sothat the operations can be systematically planned, which will reduce the in-between costs. Electric vehicles will reduce the air pollution, hence initial operating costs are understandable since the long-term implications outweigh the costs.

- Consumption level $\left(C_{13}\right)$ : Modrak and Soltysova [82] studied the operational complexity measure. The measure of consumption level denotes how affluent the people in a particular locality are. In the case that consumption level in an area is high, it can be expected that people will be more willing to go to further distances in search of more options. A charging station can be built in a high consumption area since the throng of people will have more ways of traveling and procuring their wants.

- Construction cost $\left(C_{14}\right)$ : Manerba, Mansini and Perboli [83] researched the capacitated supplier selection problem considering total quantity discount policy and activation costs under uncertainty. Construction cost varies with the location, and to make the charging station a success, the initial fixed cost should be minimized as much as possible. If the location is well-connected by various transportation facilities, then the cost of transferring the construction materials will decrease, which will decrease the construction cost and the overall profitability of the charging station will increase initially. 
- Public facilities $\left(C_{15}\right)$ : Kinay et al. [84] studied multi-criteria chance-constrained capacitated single source discrete facility location problems. Public facilities refer to schools, colleges, grocery stores, shopping malls, bus stops and the other everyday amenities which are used by commoners on a mass scale. In the case of a charging station being built near a location with a large density of public facilities, it will act as a boon since money will frequently change hands and thereby develop the area.

\subsubsection{Environmental Factors $\left(C_{2}\right)$}

This refers to those factors which will influence the immediate surroundings of the charging station. A clean and green environment helps in resonating the theme of electric vehicles and thereby makes a charging station built in such a location a success.

- Generation of noise and air pollution (GNAP) $\left(C_{21}\right)$ : In the current scenario, noise and air pollution are considered bigger hindrances than other forms of pollution. This is because they are experienced daily, which results in greater damage due to them. Electric vehicles will help in reducing both, since the batteries of the vehicles will not cause air pollution or make noise while being on the road.

- Petrol stations $\left(C_{22}\right)$ : The availability of petrol stations nearby signifies a greater number of vehicles in the area. Building a charging station near a petrol station will cause an increase in the number of vehicles and people visiting the area and thereby turn out to be more profitable since the cost will be less.

- Transportation stations $\left(C_{23}\right)$ : These refer to the various bus stops, bicycle charging stations, railway stations, car stops, and tram stops. The greater the frequency of the transportation vehicles, the more will be its impact on the environment since every form of transportation will bring more people, eventually harming the environment. Electric vehicles, on the other hand, help in the easy transportation of people without harming the environment.

\subsubsection{Traffic Factors $\left(C_{3}\right)$}

This refers to those sets of factors which are only noticeable when there is a huge population in the area. A charging station which takes into consideration the traffic factors is one which will be able to have huge implications on the state of travel in the area.

- Number of roads $\left(C_{31}\right)$ : Yao, Bai and Xu [81] studied the impact of the number of roads on China's thermal power industry. The number of roads stands for the various options which the vehicles can take in the case of congestion or for availing a shorter reach time. If the charging station is strategically built near an intersection of heavytraffic roads, then it will help the drivers be more at ease while driving since they will have a backup nearby.

- $\quad$ Road potency $\left(C_{32}\right)$ : Hosseini and Sarder [85] studied the road potency for optimal site selection using a Bayesian network model. The higher the number of vehicles in the region, the greater the footfall will be, which will eventually increase the success rate of the charging station.

- Parking areas $\left(C_{33}\right)$ : The increase in parking areas will lead to an increase in the use of electric vehicles, since one of the major thoughts which arises in a prospective buyer's mind is where one will park the vehicle. If the charging station is built near a parking area, then the vehicle owners can directly charge and park it.

\subsubsection{Societal Factors $\left(C_{4}\right)$}

With the advancement in science and technology, the factors promoting wellness of human life have taken a back seat. The societal factors point out the major problems which may be looked at to improve the quality of the society at large.

- Adverse impact of noise and electromagnetic fields $(\mathrm{AI})\left(\mathrm{C}_{41}\right)$ : (Due to the construction of the electric vehicle charging station). An electric vehicle charging station has a constant aura of noise and an electromagnetic field surrounding it during the construction 
phase which might cause a certain category of people to develop problems. If proper measures can be taken in the initial stage, then this impact may be minimized since public health is of utmost importance.

- Population density $\left(C_{42}\right)$ : This stands for the number of people living in each unit of area. When the population density in a locality is high, it shows that the area is overcrowded. There will be more consumption in such an area and the construction cost will also be high, but the quality of life will usually be low. The need of transportation in such an area is usually very high and an electric vehicle charging station constructed in such an area may just be what the people need.

Tables 1 and 2 describes the factors, sub-factors and alternatives considered for this research.

Table 1. Factors and sub-Factors considered in the present study.

\begin{tabular}{ll}
\hline Factors & Sub-Factors \\
\hline & Land cost $\left(C_{11}\right)$ \\
Economic Factors $\left(C_{1}\right)$ & Operating and management cost $(\mathrm{OMC})\left(C_{12}\right)$ \\
& Consumption level $\left(C_{13}\right)$ \\
& Construction cost $\left(C_{14}\right)$ \\
& Public facilities $\left(C_{15}\right)$ \\
\hline & GNAP $\left(C_{21}\right)$ \\
Environmental Factors $\left(C_{2}\right)$ & Petrol stations $\left(C_{22}\right)$ \\
& Transportation stations $\left(C_{23}\right)$ \\
\hline & Number of roads $\left(C_{31}\right)$ \\
Traffic Factors $\left(C_{3}\right)$ & Road potency $\left(C_{32}\right)$ \\
& Parking areas $\left(C_{33}\right)$ \\
\hline & Adverse impact of noise and electromagnetic \\
Scheme 4 & fields $($ AI $)\left(C_{41}\right)$ \\
& Population density $\left(C_{42}\right)$ \\
\hline
\end{tabular}

Table 2. Alternatives selected in the study and their corresponding nearby location, latitude and longitude.

\begin{tabular}{lll}
\hline Alternative & Nearby Location & Latitude and Longitude \\
\hline 1. Dasnagar & HP petrol pump (Debi Service station) & $22.599152,88.307854$ \\
\hline 2. Santragachi & HPCL petrol pump & $22.586515,88.276026$ \\
\hline 3. Belgachia & Petrol pump & $22.603168,88.323001$ \\
\hline 4. Howrah Maidan & Near Kabra stores & $22.581972,88.332230$ \\
\hline 5. Liluah & Sur petrol pump & $22.625105,88.350044$ \\
\hline 6. Kadamtala & HP petrol pump & $22.587778,88.320151$ \\
\hline 7. Shibpur & Chowrabasti, Shibpur & $22.562826,88.326159$ \\
\hline 8. Salkia & Malipanchghara & $22.600887,88.349325$ \\
\hline 9. Bakultala, Shibpur & Botanical Garden west end & $22.564016,88.288795$ \\
\hline 10. Belur & SSBPCL petrol pump & $22.639311,88.350857$ \\
\hline
\end{tabular}

Figure 3 represents the hierarchical framework of the problem in the study.

The rural, urban and total population for the census year starting from 2001 and 2011 has been represented in a graph (Figure 4). In this figure, the projected rural, urban and total population also been forecasted for the years 2021, 2031, 2041 and 2051 in a chronological way. The graph clearly indicates a consistent increase in the population from 4.23 million in 2001 to 6.60 million in 2051 (projected) with a sharp increase in the urban population, and the urban population growth is much higher than the rural, which 
indicates higher increasing infrastructural demand. The projected population made us think about the future transport services in the area.

\section{Selection of the best site for $\mathrm{E}$ vehicle charging}
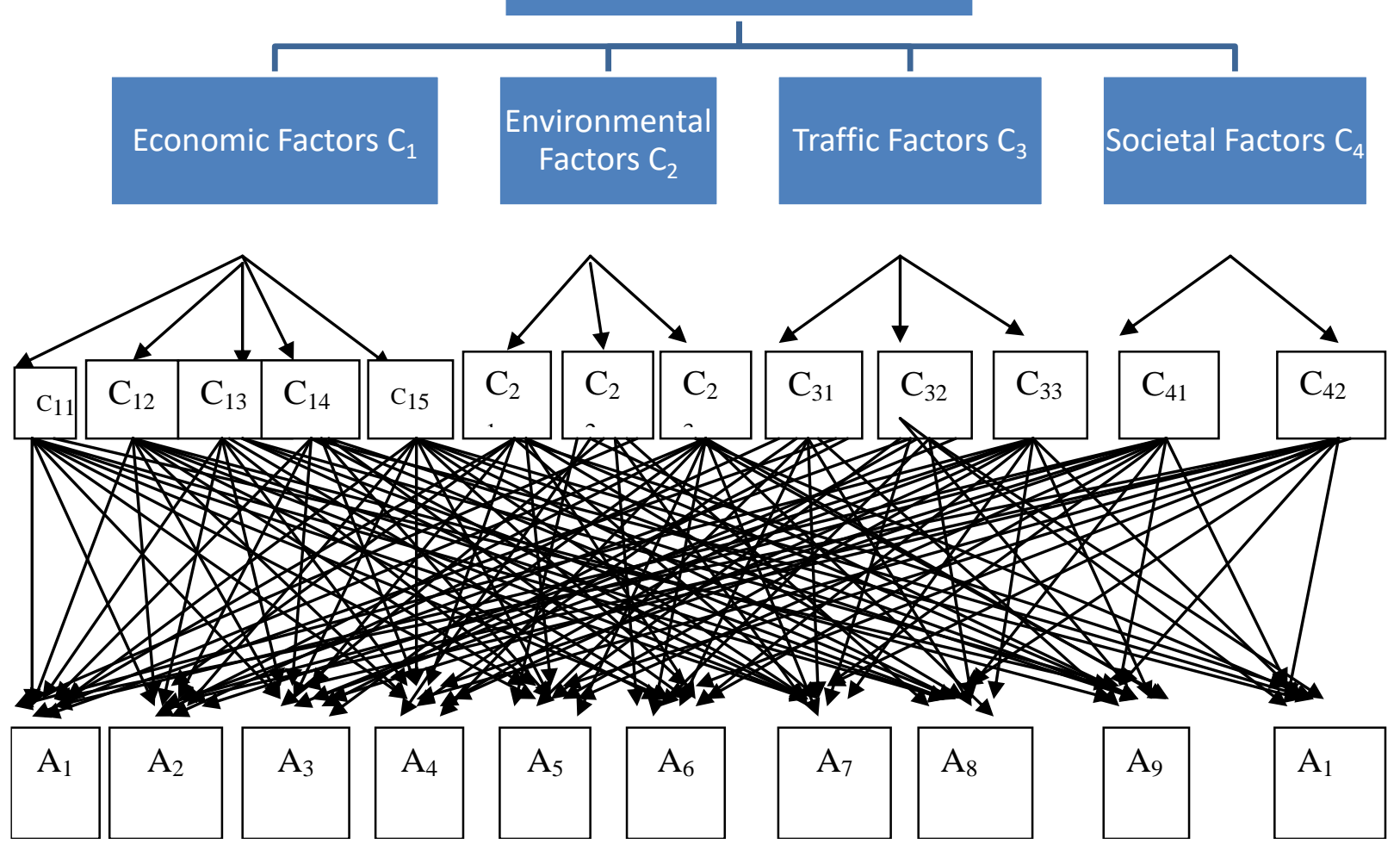

Figure 3. Hierarchical structure of the problem.

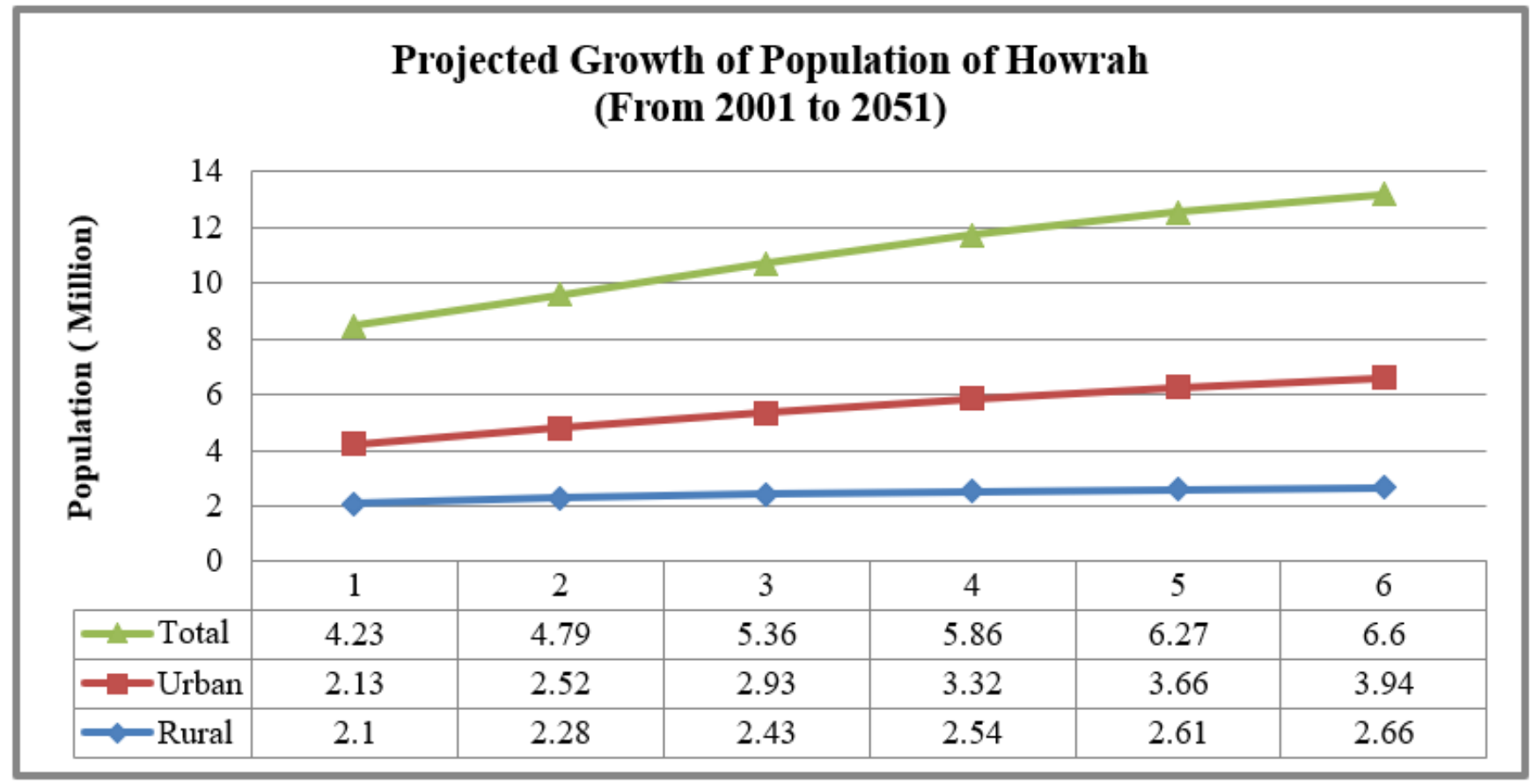

Figure 4. Projected growth of the population of rural and urban areas of the Howrah district. 
Urbanization is considered one of the most noteworthy anthropogenic inputs of the environmental framework, and thus the present study considered the spatio-temporal characteristics of urban growth and its inference in the transport of Howrah. The built-up land (Figure 5) has been generated using the NDBI (normalized difference built-up index) with the following equation NDBI = MIR $-($ NIR/MIR $)+$ NIR $(Z h a, 2003)$ [86]. Here, NIR is anear-infrared band such as ETM+ and TM, and LISSIII is a band no.4; MIR is a middle infrared band such as ETM+ and TM and LISSIII is a band no.5.The index is based on the unique spectral response of built-up lands that have a higher reflectance in the MIR wavelength range as compared to that in the NIR wave length range. Thereafter, the NDBI mapping has been prepared to understand the level of urbanization from 2000 (Figure 5a) to 2010 (Figure 5b) in the study area. It helps to correlate the changes in land use patterns and its consequences to the water storage of the study area. The NDBI values range from -1 to +1 . Very low values of the NDBI $(0.1$ and below) correspond to non-urban features, while higher values indicate the covering of areas of impervious surfaces such as asphalt and concrete. To understand the levels of urbanization, the NDBI values have categorized into five zones, which range from -0.96 to 0.45 in 2000 and from -0.95 to 0.71 in 2010 . The result with a negative value of NDBI represents the water bodies and vegetation covers, whereas the higher and positive values represent the build-up areas. The map of the year 2000 indicates a huge range of water bodies spread all over the district along with the two major rivers; the Rupnarayan River in west and south west and the Bhagirathi-Hooghly River in the east and south-east side. The major built-up areas are mostly concentrated over the north-east and north-west corners of the district covering the Bally-Jagacha and Udaynarayanpur blocks, respectively.

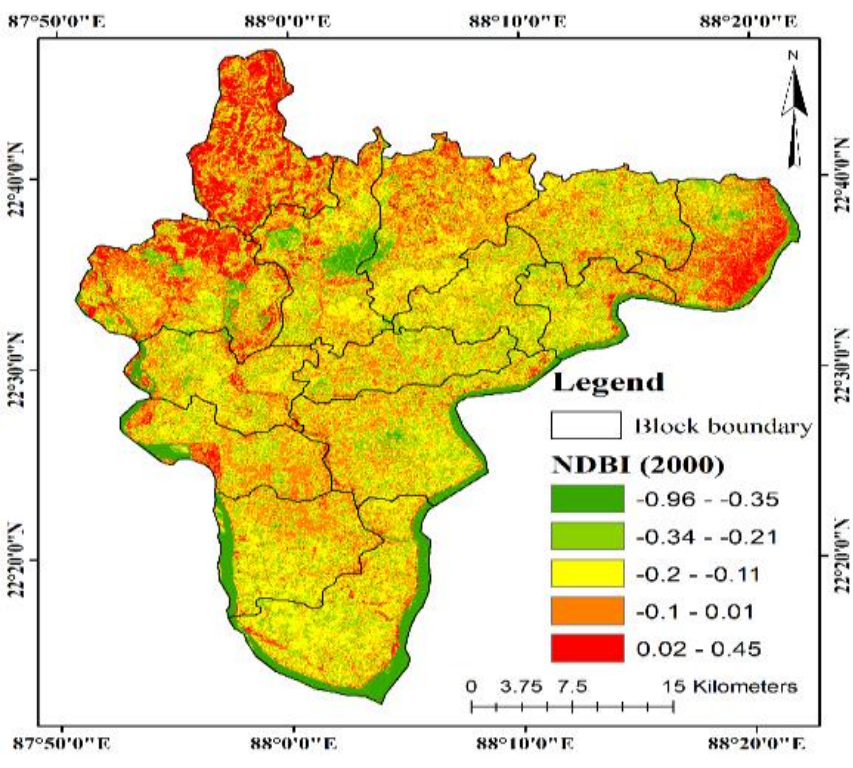

(a)

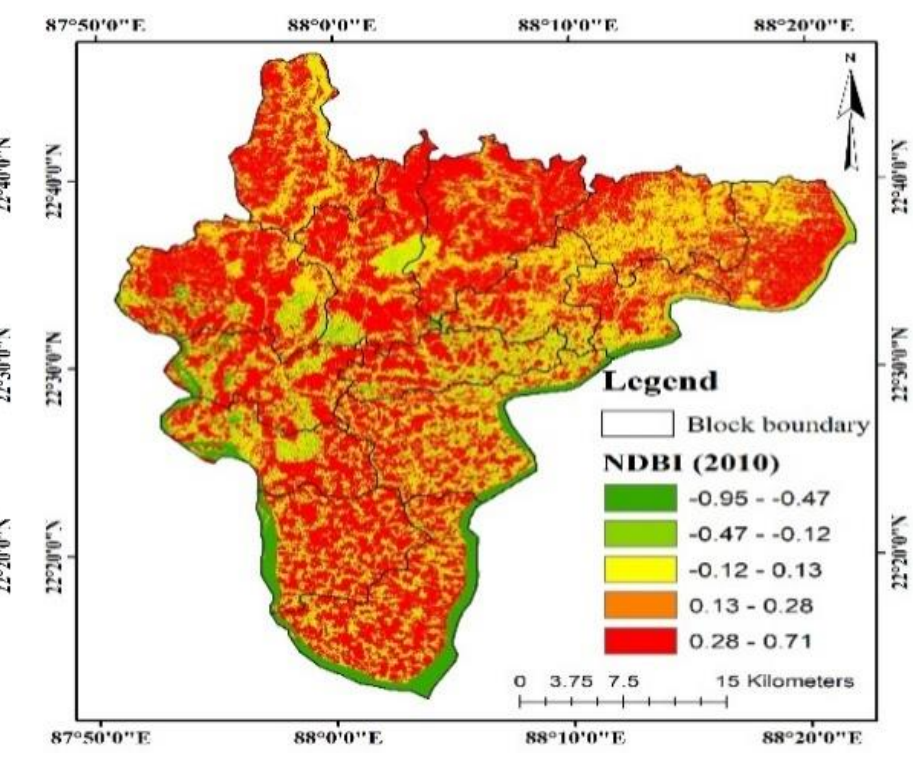

(b)

Figure 5. Normalized difference built-up index mapping for level of urbanization during (a) 2000 (b) 2010.

The transport network of the Howrah district is mapped (Figure 6) and the closest census towns (Figure 7) to the Howrah Municipal Corporation (HMC) were also plotted to understand the importance of daily communication with the Howrah station or surrounding areas. The railway and the road transport connectivity with the Howrah station, which is located in the HMC, is very good. A large number of daily commuters are traveling to the area, mostly for economic and educational purposes. It indicates the concentration of traffic in the area, and in turn increases the public transport connectivity as well as the requirement for improving the local transport system. 


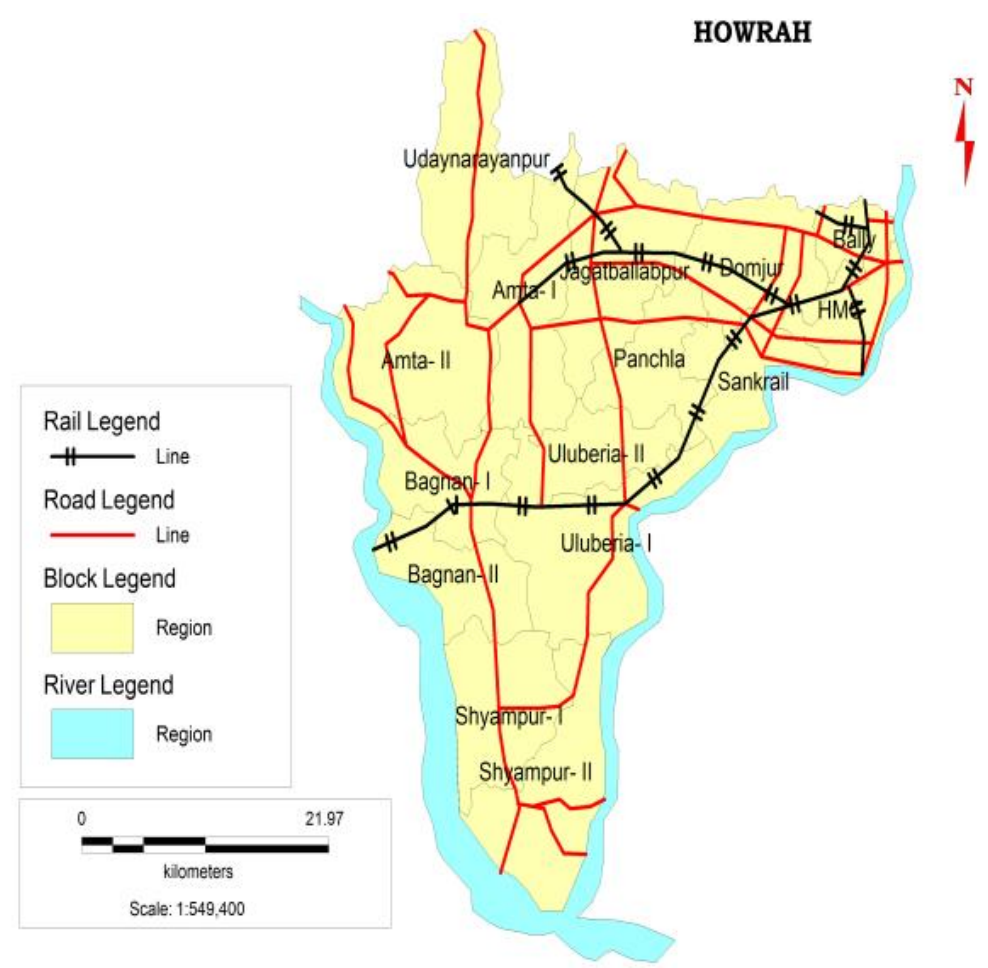

Figure 6. Transport Network in and around Howrah.

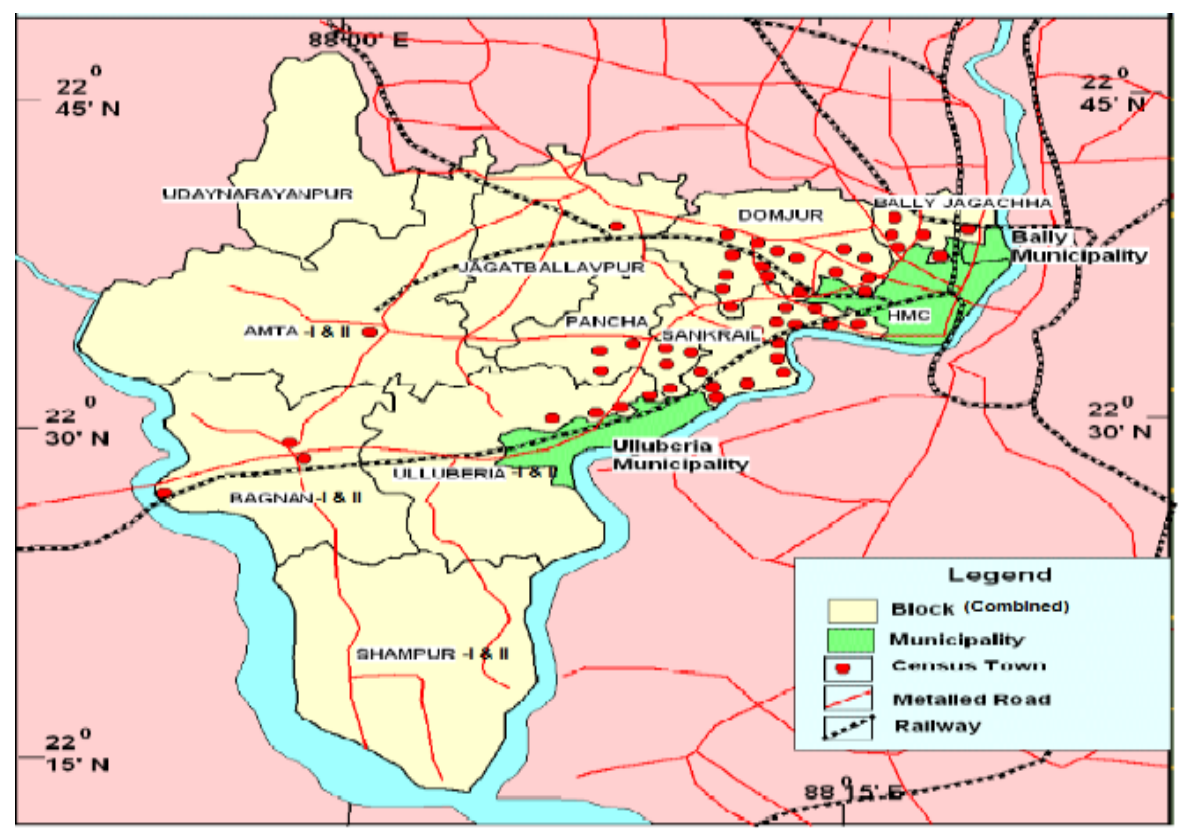

Figure 7. Transport Network of Howrah district. Along with the Census Town.

The ten selected points/locations (Figure 8) were mapped in the HMC to understand the spatial coverage and important transport nodes in the area of the current study. The population distribution of each of the 66 wards was also mapped (Figure 9) to observe the population pressure, which is also able to justify the present selection of the ten locations for the study. Most of the selected locations are in densely populated areas, where the public and local transport services are becoming very essential. Furthermore, the Howrah Maidan $\left(S_{4}\right)$ and Salkia $\left(S_{8}\right)$ are highly densely populated (Figure 9$)$ and thus very important in terms of transport services, whereas, Liluah $\left(S_{5}\right)$, Belur $\left(S_{10}\right)$ and Shibpur $\left(S_{7}\right)$ belong to highly densely populated and Kadamtala $\left(S_{6}\right)$, Bakultala $\left(S_{9}\right)$, Belgachia $\left(S_{3}\right)$ belong to 
moderately populated and Dasnagar $\left(S_{1}\right)$ and Santragachi $\left(S_{2}\right)$ belong to comparatively less populated among the ten points. But all these points are almost equally important and essential in terms of either population or transport or both. Sub criteria scores of each location has been represented in Table 3 .

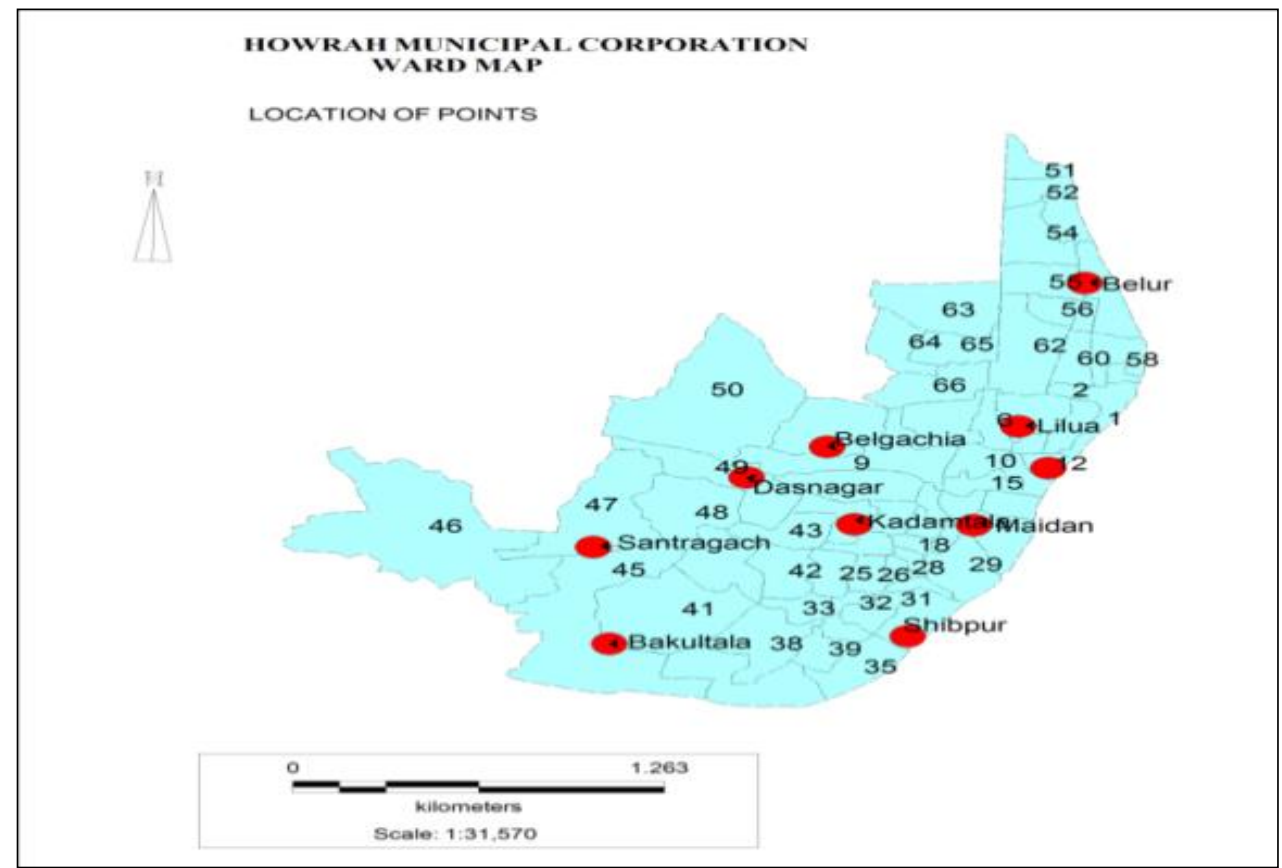

Figure 8. Location of points in HMC.

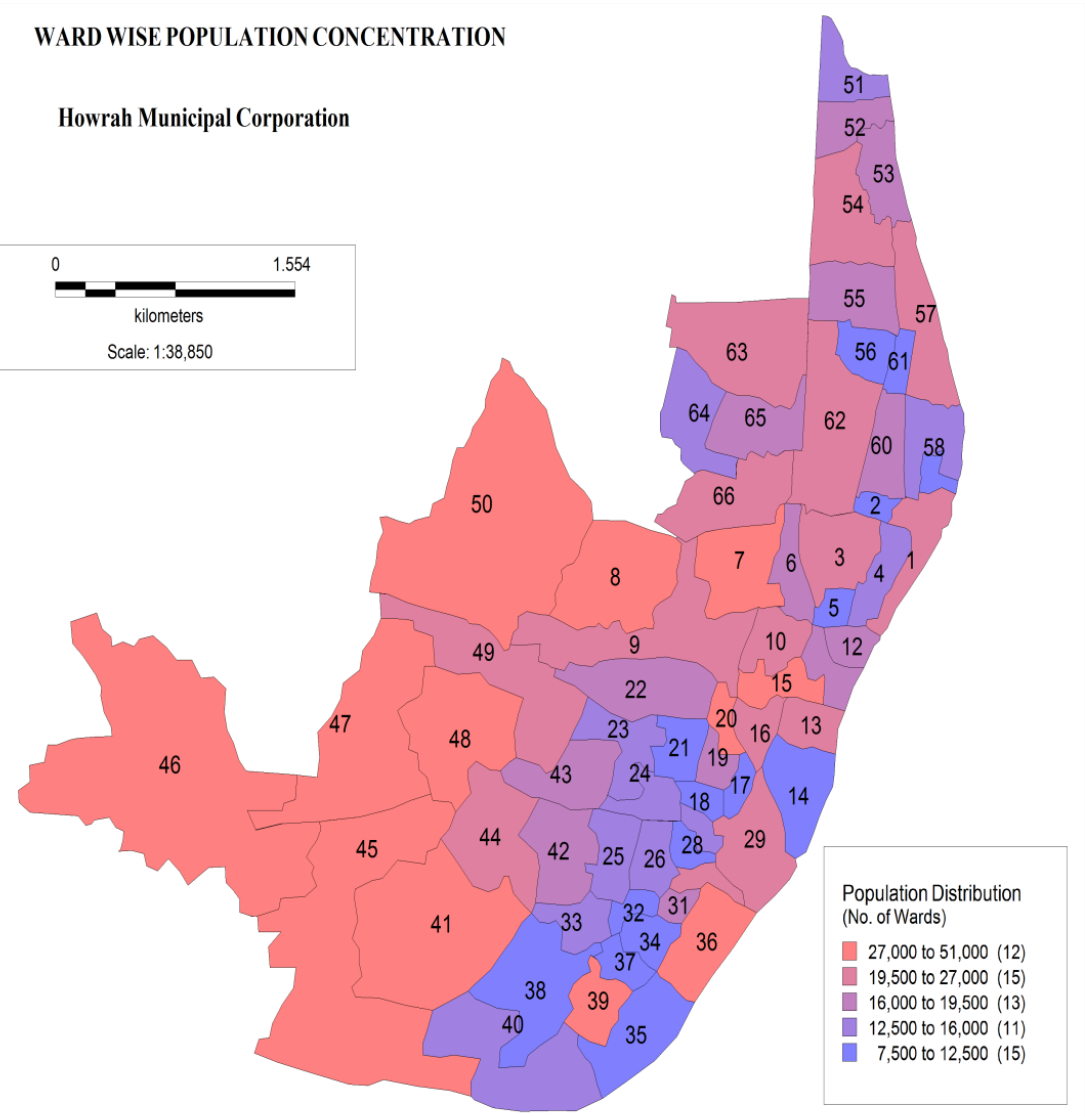

Figure 9. Ward wise population distribution of HMC. 
Table 3. Sub-factors taken for the study.

\begin{tabular}{|c|c|c|c|c|c|c|}
\hline \multicolumn{2}{|c|}{ Criteria } & \multicolumn{5}{|c|}{ Sub-Criteria and Score } \\
\hline \multirow{2}{*}{ Land cost } & Cost in Million/720 $\mathrm{ft}^{2}$ ) & $<1.50$ & $1.50-2.50$ & $2.50-3.50$ & $3.50-4.50$ & $>4.50$ \\
\hline & Score & 1 & 3 & 5 & 7 & 9 \\
\hline \multicolumn{2}{|c|}{ Operating and Management cost } & \multicolumn{5}{|c|}{ In a scale of $1,3,5,7,9$} \\
\hline \multicolumn{2}{|c|}{ Consumption Level } & \multicolumn{5}{|c|}{ In a scale of $1,3,5,7,9$} \\
\hline \multicolumn{2}{|c|}{ Construction cost } & \multicolumn{5}{|c|}{ In a scale of $1,3,5,7,9$} \\
\hline \multicolumn{2}{|c|}{ Public facilities } & \multicolumn{5}{|c|}{ In a scale of $1,3,5,7,9$} \\
\hline \multicolumn{2}{|c|}{ Emission of Greenhouse gases } & \multicolumn{5}{|c|}{ In a scale of $1,3,5,7,9$} \\
\hline \multirow[t]{2}{*}{ Petrol stations } & $\begin{array}{l}\text { (Distance in mt.) } \\
\text { (Using GIS) }\end{array}$ & $<200$ & $200-400$ & $400-600$ & $600-800$ & $>800$ \\
\hline & Score & 9 & 7 & 5 & 3 & 1 \\
\hline \multirow[t]{2}{*}{ Transportation stations } & $\begin{array}{l}\text { (Distance in mt.) } \\
\text { (Using GIS) }\end{array}$ & $<250$ & $250-500$ & $500-750$ & $750-1000$ & $>1000$ \\
\hline & Score & 9 & 7 & 5 & 3 & 1 \\
\hline \multirow{2}{*}{ Population density } & (persons $/ \mathrm{km}^{2}$ ) & $<10,000$ & $10,000-13,000$ & $13,000-16,000$ & $16,000-19,000$ & $>19,000$ \\
\hline & Score & 1 & 3 & 5 & 7 & 9 \\
\hline \multicolumn{2}{|c|}{ Number of Roads } & \multicolumn{5}{|c|}{ Crisp value location wise } \\
\hline \multicolumn{2}{|c|}{ Road Potency } & \multicolumn{5}{|c|}{ In a scale of $1,3,5,7,9$} \\
\hline \multicolumn{2}{|c|}{ Parking Areas } & \multicolumn{5}{|c|}{ In a scale of $1,3,5,7,9$} \\
\hline \multicolumn{2}{|c|}{$\begin{array}{l}\text { Adverse impact of noise and electromagnetic field due to } \\
\text { construction of electric vehicle charging station }\end{array}$} & \multicolumn{5}{|c|}{ In a scale of $1,3,5,7,9$} \\
\hline
\end{tabular}

Linguistic variables in HFN required for the comparison of factors and sub-factors are shown in Table 4.

Table 4. Linguistic term in HFN 1-9 scale.

\begin{tabular}{ccc}
\hline Linguistic Terms & 1-9 Scale & Hexagonal Fuzzy Number (HFN) \\
\hline Equally Important (EI) & 1 & 1 \\
\hline Weakly Important (WI) & 2 & $(1.1,1.2,1.3,1.4,1.5,1.6)$ \\
\hline Moderately Important (MI) & 3 & $(1.8,2,2.2,2.5,2.7,3)$ \\
\hline Strongly Important (SI) & 5 & $(2.9,3,3.2,3.3,3.5,3.9)$ \\
\hline Very Strongly Important (VSI) & 7 & $(3.6,4,4.1,4.4,4.5,4.8)$ \\
\hline Absolutely Important (AI) & 9 & $(4.6,4.8,5,5.2,5.4,5.7)$ \\
\hline Absolutely Unimportant (AUI) & $1 / 9$ & $(0.21,0.22,0.23,0.24,0.25,0.28)$ \\
\hline Very Strongly Unimportant & $1 / 7$ & $(0.26,0.28,0.3,0.31,0.33,0.34)$ \\
\hline Strongly Unimportant & $1 / 5$ & $(0.33,0.37,0.4,0.45,0.5,0.55)$ \\
\hline Moderately Unimportant & $1 / 3$ &
\end{tabular}
Table 5 .

Comparison between factors in linguistic variables given by two DMs is presented in

The above Table 6 represents preference of factors in defuzzified form using Equation (18).Normalized matrix is obtained using Equation (20); priority weight of factors are calculated using Equation (21). Societal factors obtain the maximum weight of 0.430, followed by environmental factor 0.37 , followed by traffic factor 0.139 and economic factor 0.065 .

Table 5. Representation of comparison between factors.

\begin{tabular}{ccccccccc}
\hline Factors & \multicolumn{2}{c}{ Economic Factors $\left(C_{1}\right)$} & \multicolumn{2}{c}{ Environmental Factors $\left(\boldsymbol{C}_{2}\right)$} & \multicolumn{2}{c}{ Traffic Factors $\left(\boldsymbol{C}_{3}\right)$} & \multicolumn{2}{c}{ Societal Factors $\left(\boldsymbol{C}_{4}\right)$} \\
\hline Decision Makers $(\mathrm{DMs})$ & DM1 & DM2 & DM1 & DM2 & DM1 & DM2 & DM1 & DM2 \\
\hline Economic Factors $\left(C_{1}\right)$ & EI & EI & AUI & VSUI & SUI & VSUI & SUI & AUI \\
\hline Environmental Factors $\left(C_{2}\right)$ & AI & VSI & EI & EI & SI & VSI & EI & MUI \\
\hline Traffic Factors $\left(C_{3}\right)$ & SI & VSI & SUI & VSUI & EI & EI & SUI & VSUI \\
\hline Societal Factors $\left(C_{4}\right)$ & SI & AI & EI & MI & SI & VSI & EI & EI \\
\hline
\end{tabular}

Note. Two DMs are considered here in the study, their opinions are combined using Equation (19). 
Table 6. Representation of preference of factors in defuzzified form using Equation (18).

\begin{tabular}{ccccc}
\hline FACTORS & ECONOMIC & ENVIRONMENTAL & TRAFFIC & SOCIETAL \\
\hline ECONOMIC & 1 & 0.22 & 0.27 & 0.22 \\
\hline ENVIRONMENTAL & 4.7 & 1 & 3.8 & 0.74 \\
\hline TRAFFIC & 3.8 & 0.27 & 1 & 0.27 \\
\hline SOCIETAL & 3.8 & 1.74 & 3.8 & 1 \\
\hline
\end{tabular}

The weight of factors obtained is represented in Table 7.

Table 7. Representation of the priority weight of factors.

\begin{tabular}{ccccccc}
\hline FACTORS & ECONOMIC & ENVIRONMENTAL & TRAFFIC & SOCIETAL & SUM & E/Sum \\
\hline ECONOMIC & 0.065 & 0.081 & 0.038 & 0.095 & 0.278 & 4.276795 \\
\hline ENVIRONMENTAL & 0.305 & 0.366 & 0.529 & 0.318 & 1.518 & 4.148243 \\
\hline TRAFFIC & 0.247 & 0.099 & 0.139 & 0.116 & 0.601 & 4.313789 \\
\hline SOCIETAL & 0.247 & 0.637 & 0.529 & 0.430 & 1.843 & 4.287043 \\
\hline
\end{tabular}

Using Equation (22), C.I is calculated to be 0.08. For R.I, as $n=4$, the value is 0.09 . Thus using Equation (23), C.R $=\frac{0.08}{0.9}=0.09<0.1$, hence the matrix is consistent.

In the similar way, the comparison analysis of sub-factors with the help of two DMs has been calculated. The fuzzy weight of factors, sub-factors and global fuzzy weight are represented in Table 8.

Table 8. Hexagonal fuzzy weights of factors, sub-factors and global weight.

\begin{tabular}{ccc}
\hline Factors Fuzzy Weight & Sub-Factor Fuzzy Weight & Global Weight \\
\hline & $C_{11}=(0.06,0.07,0.1,0.11,0.18,0.20)$ & $C_{11}=(0.003,0.003,0.007,0.008,0.018,0.021)$ \\
& $C_{12}=(0.09,0.11,0.16,0.17,0.29,0.32)$ & $C_{12}=(0.004,0.005,0.011,0.012,0.028,0.035)$ \\
$C_{1}=(0.04,0.05,0.07,0.07,0.10,0.11)$ & $C_{13}=(0.13,0.15,0.24,0.25,0.41,0.46)$ & $C_{13}=(0.006,0.007,0.016,0.018,0.040,0.050)$ \\
& $C_{14}=(0.03,0.04,0.06,0.06,0.09,0.10)$ & $C_{14}=(0.001,0.002,0.004,0.004,0.009,0.011)$ \\
& $C_{15}=(0.23,0.27,0.41,0.43,0.68,0.76)$ & $C_{15}=(0.01,0.012,0.027,0.030,0.067,0.082)$ \\
\hline & $C_{21}=(0.084,0.09,0.114,0.125,0.155,0.177)$ & $C_{21}=(0.02,0.02,0.04,0.05,0.08,0.10)$ \\
$C_{2}=(0.21,0.23,0.35,0.38,0.54,0.58)$ & $C_{22}=(0.17,0.19,0.24,0.26,0.34,0.39)$ & $C_{22}=(0.04,0.04,0.08,0.10,0.19,0.23)$ \\
& $C_{23}=(0.41,0.46,0.59,0.65,0.83,0.93)$ & $C_{23}=(0.08,0.11,0.21,0.24,0.45,0.54)$ \\
\hline & $C_{31}=(0.07,0.08,0.1 .0 .11,0.14,0.16)$ & $C_{31}=(0.007,0.008,0.014,0.016,0.03,0.035)$ \\
$\left.C_{3}=0.09,0.10,0.14,0.15,0.20,0.22\right)$ & $C_{32}=(0.493,0.55,0.66,0.71,0.86,0.96)$ & $C_{32}=(0.045,0.054,0.09,0.104,0.18,0.21)$ \\
& $C_{33}=(0.142,0.16,0.197,0.214,0.27,0.31)$ & $C_{33}=(0.013,0.015,0.027,0.031,0.055,0.07)$ \\
\hline & $C_{41}=(0.3,0.3,0.49,0.50,0.82,0.87)$ & $C_{41}=(0.08,0.082,0.202,0.226,0.57,0.66)$ \\
$C_{4}=(0.26,0.27,0.42,0.45,0.69,0.76)$ & $C_{42}=(0.3,0.3,0.43,0.43,0.61,0.63)$ & $C_{42}=(0.08,0.082,0.18,0.195,0.42,0.48)$ \\
\hline
\end{tabular}

The linguistic terms used in this study for the rating of alternatives with respect to sub-factors. Preference of alternatives with respect to sub-factors are expressed in linguistic terms, scores and crisp values are depicted in Table 9. Note 2. The sub-factors $\left(C_{22}\right)$ and $\left(C_{23}\right)$ are assigned score using Table 3; later, it is converted to HFN. A score of 9 implies "very high" and so on. 
Table 9. Comparison analysis in linguistic variables for preference of alternatives with respect to sub-factors.

\begin{tabular}{|c|c|c|c|c|c|c|c|c|c|c|c|c|c|}
\hline \multirow{2}{*}{ Locations } & \multicolumn{13}{|c|}{ Sub-Factors } \\
\hline & $C_{11}$ & $C_{12}$ & $C_{13}$ & $C_{14}$ & $C_{15}$ & $C_{21}$ & $C_{22}$ & $C_{23}$ & $C_{31}$ & $C_{32}$ & $C_{33}$ & $C_{41}$ & $C_{42}$ \\
\hline Dasnagar $\left(S_{1}\right)$ & $\mathrm{M}$ & $\mathrm{L}$ & $\mathrm{L}$ & M & $\mathrm{M}$ & $\mathrm{VL}$ & 9 & 9 & 3 & $\mathrm{H}$ & $\mathrm{M}$ & $\mathrm{VL}$ & $\mathrm{L}$ \\
\hline Santragachi $\left(S_{2}\right)$ & $\mathrm{H}$ & $\mathrm{L}$ & $\mathrm{L}$ & M & $\mathrm{L}$ & $\mathrm{VL}$ & 9 & 7 & 1 & $\mathrm{VH}$ & $\mathrm{H}$ & VL & $\mathrm{L}$ \\
\hline Belgachia $\left(S_{3}\right)$ & $\mathrm{M}$ & $\mathrm{M}$ & $\mathrm{VL}$ & $\mathrm{M}$ & $\mathrm{VL}$ & $\mathrm{H}$ & 9 & 3 & 2 & $\mathrm{H}$ & $\mathrm{L}$ & $\mathrm{H}$ & $\mathrm{M}$ \\
\hline Howrah Maidan $\left(S_{4}\right)$ & $\mathrm{VH}$ & $\mathrm{VH}$ & $\mathrm{VH}$ & $\mathrm{VH}$ & $\mathrm{VH}$ & $\mathrm{VH}$ & 7 & 7 & 4 & $\mathrm{VH}$ & $\mathrm{L}$ & $\mathrm{VH}$ & $\mathrm{VH}$ \\
\hline Liluah $\left(S_{5}\right)$ & $\mathrm{H}$ & $\mathrm{H}$ & M & $\mathrm{VH}$ & $\mathrm{VH}$ & $\mathrm{H}$ & 9 & 5 & 1 & $\mathrm{M}$ & $\mathrm{L}$ & $\mathrm{H}$ & $\mathrm{H}$ \\
\hline Kadamtala $\left(S_{6}\right)$ & $\mathrm{H}$ & $\mathrm{H}$ & $\mathrm{H}$ & $\mathrm{H}$ & $\mathrm{H}$ & $\mathrm{H}$ & 9 & 1 & 2 & $\mathrm{M}$ & $\mathrm{L}$ & $\mathrm{VH}$ & $\mathrm{M}$ \\
\hline Shibpur $\left(S_{7}\right)$ & $\mathrm{H}$ & $\mathrm{H}$ & $\mathrm{VH}$ & $\mathrm{H}$ & $\mathrm{H}$ & $\mathrm{M}$ & 9 & 1 & 1 & $\mathrm{M}$ & $\mathrm{L}$ & $\mathrm{M}$ & $\mathrm{H}$ \\
\hline Salkia $\left(S_{8}\right)$ & $\mathrm{H}$ & $\mathrm{VH}$ & $\mathrm{VH}$ & $\mathrm{VH}$ & $\mathrm{H}$ & $\mathrm{VH}$ & 5 & 1 & 2 & $\mathrm{M}$ & $\mathrm{L}$ & $\mathrm{VH}$ & $\mathrm{VH}$ \\
\hline Bakultala $\left(S_{9}\right)$ & $\mathrm{M}$ & $\mathrm{L}$ & $\mathrm{H}$ & $\mathrm{H}$ & $\mathrm{L}$ & $\mathrm{L}$ & 9 & 1 & 1 & $\mathrm{~L}$ & $\mathrm{~L}$ & $\mathrm{~L}$ & $\mathrm{M}$ \\
\hline Belur $\left(S_{10}\right)$ & $\mathrm{M}$ & M & M & $\mathrm{M}$ & $\mathrm{L}$ & $\mathrm{H}$ & 9 & 3 & 1 & $\mathrm{M}$ & $\mathrm{L}$ & $\mathrm{H}$ & $\mathrm{H}$ \\
\hline
\end{tabular}

Note: For $C_{22}, C_{23}$ and $C_{31}$ are represented with crisp numbers.

\subsection{Ranking of Alternatives Using Fuzzy AHP-TOPSIS Method}

Following the steps represented in Section 2.7, distance measure, relative closeness and the ranking of sites has been computed as depicted in Table 10.

Table 10. Representation of distance measure, relative closeness and the ranking of sites.

\begin{tabular}{ccccc}
\hline Alternatives & $\boldsymbol{L}_{\boldsymbol{g}}^{+}$ & $\boldsymbol{L}_{\boldsymbol{g}}^{-}$ & $\boldsymbol{R}_{\boldsymbol{g}}=\frac{\boldsymbol{L}_{\boldsymbol{g}}^{-}}{\boldsymbol{L}_{\boldsymbol{g}}^{-}+\mathbf{L}_{\boldsymbol{g}}^{+}}$ & Ranking \\
\hline Dasnagar $\left(S_{1}\right)$ & 0.441 & 0.264 & 0.375 & 8 \\
\hline Santragachi $\left(S_{2}\right)$ & 0.468 & 0.238 & 0.337 & 4 \\
\hline Belgachia $\left(S_{3}\right)$ & 0.271 & 0.435 & 0.616 & 1 \\
\hline Howrah Maidan $\left(S_{4}\right)$ & 0.058 & 0.647 & 0.918 & 2 \\
\hline Liluah $\left(S_{5}\right)$ & 0.184 & 0.522 & 0.739 & 6 \\
\hline Kadamtala $\left(S_{6}\right)$ & 0.302 & 0.404 & 0.572 & 5 \\
\hline Shibpur $\left(S_{7}\right)$ & 0.285 & 0.422 & 0.596 & 3 \\
\hline Salkia $\left(S_{8}\right)$ & 0.259 & 0.446 & 0.633 & 7 \\
\hline Bakultala $\left(S_{9}\right)$ & 0.379 & 0.328 & 0.464 & 3 \\
\hline Belur $\left(S_{10}\right)$ & 0.239 & 0.468 & 0.662 & \\
\hline
\end{tabular}

\subsection{Ranking of Alternatives UsingFuzzy AHP-COPRAS}

Following the steps represented in Section $2.8, R_{+g}, R_{-g}, R_{g}, R$ and ranking are computed as depicted in Table 11.

Table 11. Values of $R_{+g}, R_{-g}, R_{g}, R R$ and ranking are represented.

\begin{tabular}{cccccc}
\hline Alternatives & $\boldsymbol{R}_{+g}$ & $\boldsymbol{R}_{-g}$ & $\boldsymbol{R}_{\boldsymbol{g}}$ & $\boldsymbol{R}$ & Ranking \\
\hline Dasnagar $\left(S_{1}\right)$ & 0.68 & 0.19 & 0.691 & 77.98 & 7 \\
\hline Santragachi $\left(S_{2}\right)$ & 0.66 & 0.19 & 0.703 & 79.35 & 6 \\
\hline Belgachia $\left(S_{3}\right)$ & 0.59 & 0.08 & 0.707 & 79.82 & 5 \\
\hline Howrah Maidan $\left(S_{4}\right)$ & 0.75 & 0.06 & 0.886 & 100.00 & 1 \\
\hline Liluah $\left(S_{5}\right)$ & 0.65 & 0.07 & 0.778 & 87.82 & 2 \\
\hline Kadamtala $\left(S_{6}\right)$ & 0.55 & 0.07 & 0.680 & 76.81 & 9 \\
\hline Shibpur $\left(S_{7}\right)$ & 0.58 & 0.08 & 0.685 & 77.33 & 8 \\
\hline Salkia $\left(S_{8}\right)$ & 0.58 & 0.06 & 0.716 & 80.82 & 4 \\
\hline Bakultala $\left(S_{9}\right)$ & 0.52 & 0.10 & 0.614 & 69.34 & 10 \\
\hline Belur $\left(S_{10}\right)$ & 0.62 & 0.08 & 0.732 & 82.66 & 3 \\
\hline & & & & &
\end{tabular}




\section{Comparison Analysis and Sensitivity Analysis}

Two different MCDM techniques, fuzzy AHP-TOPSIS and fuzzy AHP-COPRAS were employed for the selection of the optimal site for aelectric vehicle charging station in and around the city of Howrah, West Bengal, India. Figure 10 denotes the comparative ranking obtained under the two methodologies, fuzzy AHP-TOPSIS and fuzzy AHPCOPRAS. We also tried to compare the alternatives ranking using the two different said proposed methods.

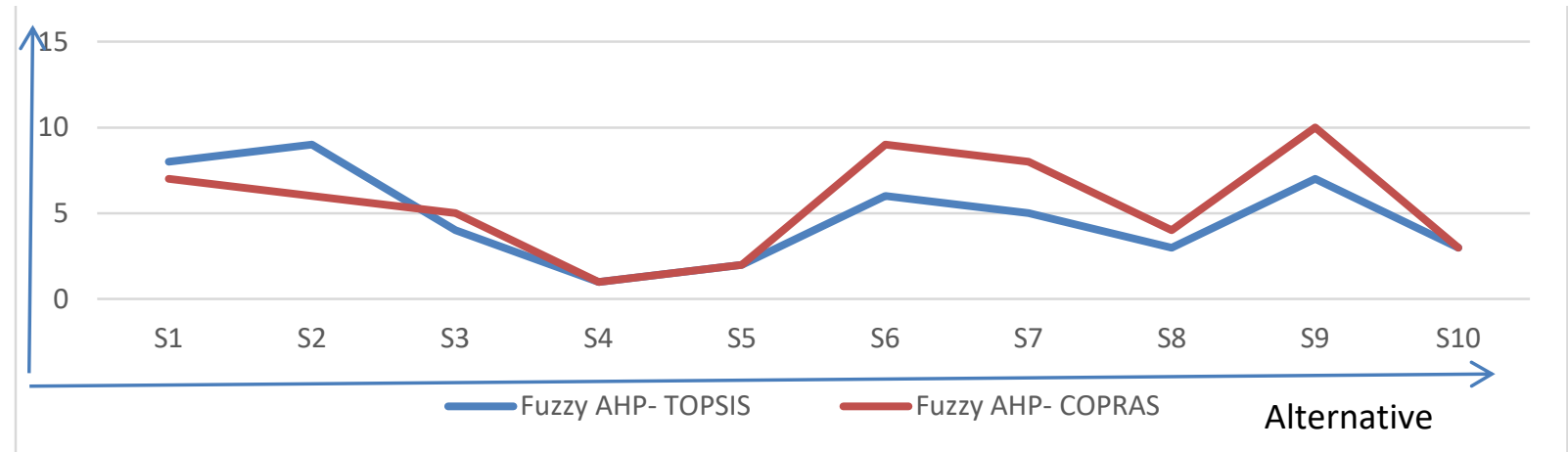

Figure 10. Representation of the ranking obtained under the two MCDM techniques.

A sensitivity analysis was conducted to see the ranking obtained under different changing conditions. Figures 11 and 12 represents the clustered column chart to compare the ranking with the interchange of the sub-factors' weight. Two different cases are taken. In the first case, the sub-factors parking facilities ' $C_{15}$ ' and population density ' $C_{42}$ ' weights were interchanged. In the second case, land cost ' $C_{11}$ ' and generation of noise and air pollution ' $C_{21}$ ' weights were interchanged. For both these cases, two different methodologies were used in this study, i.e., fuzzy AHP-TOPSIS and fuzzy AHP-COPRAS.

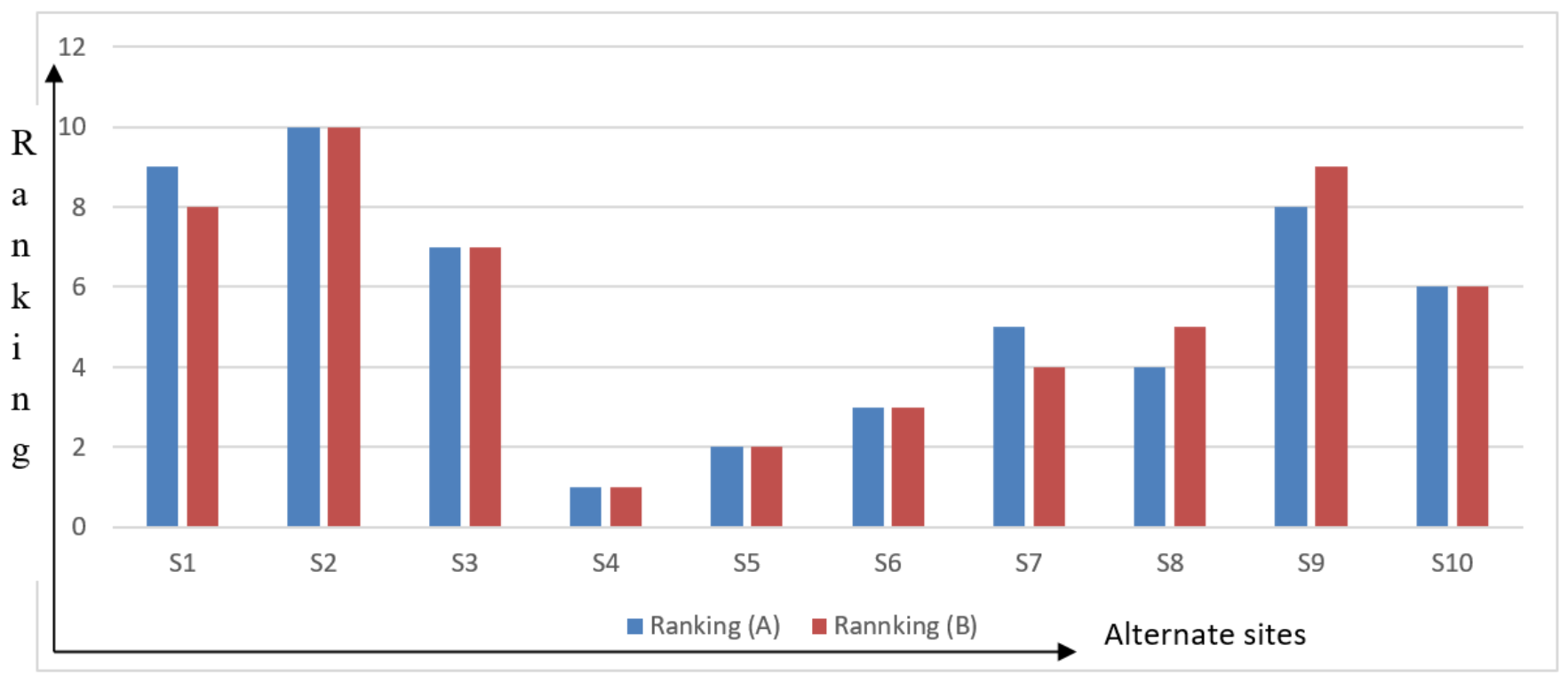

Figure 11. Sensitivity analysis ranking obtained under fuzzy AHP-TOPSIS.

Figure 11, i.e., ranking obtained by fuzzy AHP-TOPSIS under sensitivity analysis shows that the alternative $\left(S_{4}\right),\left(S_{5}\right),\left(S_{6}\right),\left(S_{10}\right),\left(S_{3}\right)$ and $\left(S_{2}\right)$ are consistent with first, second, third, fourth, fifth and sixth position, respectively, under the considered two cases, whereas following Figure 12, i.e., ranking yield by fuzzy AHP-COPRAS under sensitivity analysis shows that the sites $\left(S_{4}\right),\left(S_{5}\right),\left(S_{2}\right),\left(S_{10}\right),\left(S_{3}\right)$ and $\left(S_{9}\right)$ scores the rank of first, 
second, fifth, seventh, ninth and tenth position, respectively. The other sites' variation of rank is noticed under the sensitivity analysis and depicted in the mentioned figures.

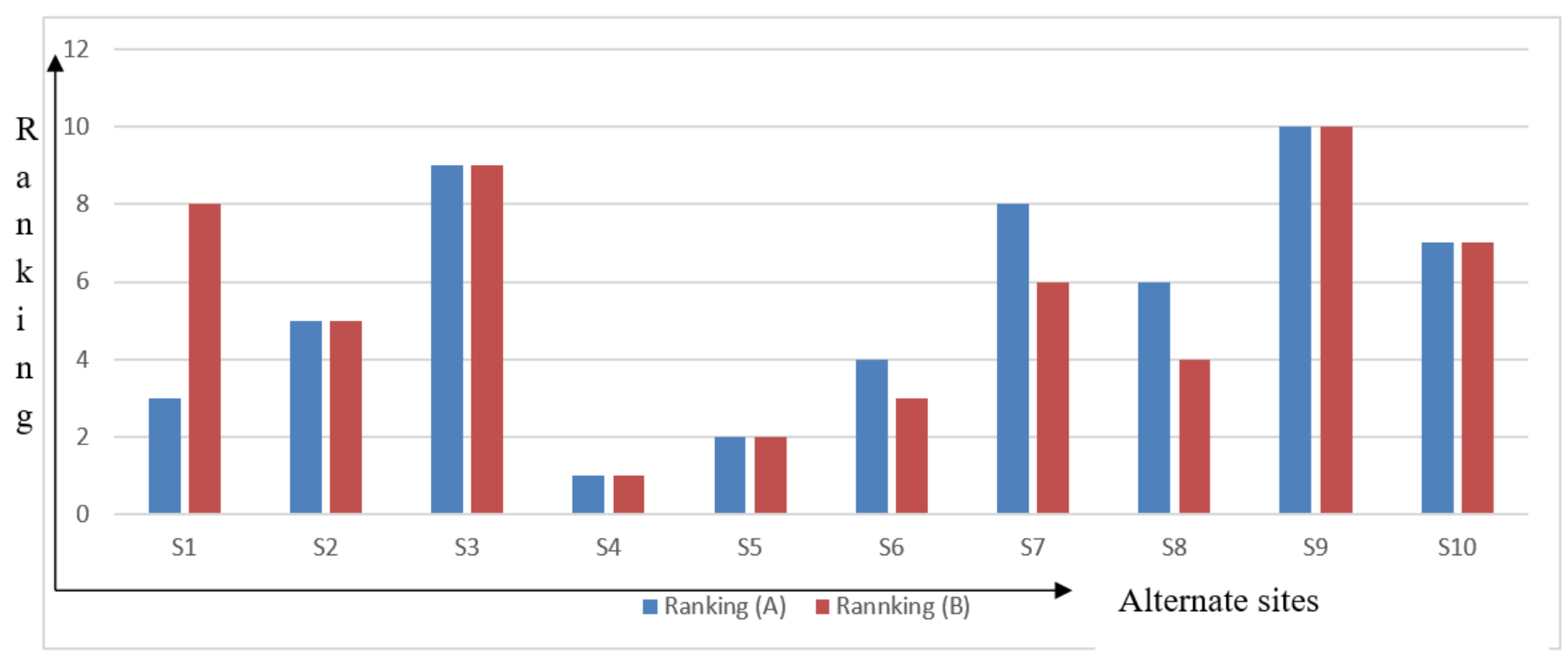

Figure 12. Sensitivity analysis ranking obtained under fuzzy AHP-COPRAS.

\section{Results and Discussion}

This section discusses the results obtained by the methodology FAHP-TOPSIS, FAHPCOPRAS and the sensitivity analysis. The ranking obtained under the two MCDM techniques yield the site "Howrah Maidan" $\left(S_{4}\right)$ as the best alternative for e-vehicle site selection followed by "Liluah" $\left(S_{5}\right)$ and "Belur" $\left(S_{10}\right)$. The FAHP-TOPSIS ranked the alternative "Belur" $\left(S_{10}\right)$ and "Salkia" $\left(S_{8}\right)$ equally at the third position. Ranking obtained for all the sites are presented in Tables 10 and 11. In the sensitivity analysis, where the sub-factors' weight are interchanged as discussed in Section 5, it is seen that the site selected "Howrah Maidan" $\left(S_{4}\right)$ consistently remains in the first position. The rankings obtained under the sensitivity analysis by the two methods are depicted in Figures 11 and 12.

\section{Conclusionsand Future Scope}

Ease of commutation, a pollution-free mode of transport, as well as employment generation are direct and indirect benefits of the e-vehicle. For developing countries where the pollution level is quite high and proportion of the roads is lower, e-vehicles can be a game changer. According to our study, considering ten locations across the city of Howrah Maidan due to its proximity to India's largest railway station Howrah and various other attributes ranked it as number one, followed by Liluah and Belur. These three locations are consistent with rank one, two and three, respectively, irrespective of the two MCDM methodologies applied in this research. High population density, enhanced level of consumerism, and the presence of various public facilities with higher footfalls led to this higher ranking.

This paper used the GIS and MCDM tools FAHP, F-TOPSIS and F-COPRAS to obtain the optimal site selection for the e-vehicle charging station. HFN has been used to give a preferential rating of factors, sub-factors and alternatives. The ranking obtained using MCDM tools are logical and scientific. The present findings provide important references for future potential work and problem solving.

For the site selection, factors such as environmental, economic, traffic, societal are incorporated with their respective sub-factors. Through this research, it is observed that the societal factor is the most significant and out of the sub-factors, population density is the most important. 
HFN is used here as it captures the hesitancy and vagueness in an efficient way. To practice the qualitative criteria evaluation for imprecise information, FAHP, F-TOPSIS and F-COPRAS are used. Comparative analysis which uses F-TOPSIS and F-COPRAS in our example has depicted consistent results. The reliability, robustness and efficiency of this methodology has also been tested through sensitivity analysis. HFN captures a wider range of linguistic terms but usage of HFN makes computation a bit longer.

In Howrah, India, a very old and unplanned city, creating e-vehicle charging infrastructure across the city is important. A site like Santragachi $\left(S_{2}\right)$ in this research which ranks lower at present could acquire a significant position due to huge infrastructural investment by the government in that area. A big railway terminus is coming up, which has the potential to change the demography of the area. Thus futuristic sub-factors can be incorporated into future research. The absence of futuristic sub-factors is a limitation at present. A larger number of decision makers based on the administrative point of view can be explored in future research. The proposed methodology used in this research can be applied in different fields such as new vendor selection, and treatment selection for new diseases where more ambiguity and uncertainty is prevalent. The other MCDM tools such as PROMETHEE, VIKOR, and WASPAS can be used in the future with intuitionistic, neutrosophic, and hesitant fuzzy numbers to yield improved, robust and practical solutions.

Author Contributions: Conceptualization, A.G., S.P.M.; methodology, S.P.M. and N.G.; software, B.K.M.; validation, A.D. and M.S.G.; formal analysis, A.G., N.G.; investigation, S.K. and A.G.; resources, B.K.M.; data curation, B.K.M. and S.P.M.; writing-original draft preparation, S.K. and A.G.; writing-review and editing, S.P.M. and N.G.; visualization, B.K.M.; supervision, A.G., S.P.M.; project administration, A.G. and S.P.M.; funding acquisition. All authors have read and agreed to the published version of the manuscript.

Funding: This research received no external funding.

Institutional Review Board Statement: Not applicable.

Informed Consent Statement: Not applicable.

Data Availability Statement: We mention the source of used data in the work.

Conflicts of Interest: The authors declare no conflict of interest.

\section{References}

1. Bilgen, S. Structure and environmental impact of global energy consumption. Renew. Sustain. Energy Rev. 2014, 38, 890-902. [CrossRef]

2. Zhao, H.R.; Guo, S.; Fu, L.W. Review on the costs and benefits of renewable energy power subsidy in China. Renew. Sustain. Energy Rev. 2014, 37, 538-549. [CrossRef]

3. Hernández, J.C.; Sutil, S.F.; Vidal, P.G.; Casas, R.C. Primary frequency control and dynamic grid support for vehicle-to-grid in transmission systems. Int. J. Electr. Power Energy Syst. 2018, 100, 152-166. [CrossRef]

4. Schoettle, B.; Sivak, M. The relative merits of battery-electric vehicles and fuel-cell vehicles. Transp. Res. Inst. Mich. 2016. Available online: http:/ / www.umich.edu/ \{\}umtriswt/PDF/UMTRI-2016-5.pdf (accessed on 15 February 2021).

5. Singh, M.; Kumar, P.; Kar, I. A multi charging station for electric vehicles and its utilization for load management and the grid support. IEEE Trans. Smart Grid 2013, 4, 1026-1037. [CrossRef]

6. Rowe, G.E.; Gardner, B.; Abraham, C.; Skippon, S.; Dittmar, H.; Hutchins, R.; Stannard, J. Mainstream consumers driving plug-in battery-electric and plug-in hybrid electric cars: A qualitative analysis of responses and evaluations. Transp. Res. Part A Policy Pract. 2012, 46, 140-153. [CrossRef]

7. Hernández, J.C.; Rodriguez, R.F.J.; Jurado, F. Modelling and assessment of the combined technical impact of electric vehicles and photovoltaic generation in radial distribution systems. Energy 2017, 141, 316-332. [CrossRef]

8. Mak, H.Y.; Rong, Y.; Shen, Z.J.M. Infrastructure planning for electric vehicles with battery swapping. Manag. Sci. 2013, 59, 1557-1575. [CrossRef]

9. Fang, Y.; Wei, W.; Mei, S.; Chen, L.; Zhang, X.; Huang, S. Promoting electric vehicle charging infrastructure considering policy incentives and user preferences: An evolutionary game model in a small-world network. J. Clean. Prod. 2020, 258, 753. [CrossRef]

10. Dericioglu, C.; Yirik, E.; Unal, E.; Cuma, M.U.; Onur, B.; Tumay, M. A review of charging technologies for commercial electric vehicles. Int. J. Adv. Automot. Technol. 2018, 2, 61-70.

11. Zivin, J.S.G.; Kotchen, M.J.; Mansur, E.T. Spatial and temporal heterogeneity of marginal emissions: Implications for electric cars and other electricity-shifting policies. J. Econ. Behav. Organ. 2014, 107, 248-268. [CrossRef] 
12. Millo, F.; Rolando, L.; Fuso, R.; Mallamo, F. Real $\mathrm{CO}_{2}$ emissions benefits and end user's operating costs of a plug-in hybrid electric vehicle. Appl. Energy 2014, 114, 563-571. [CrossRef]

13. Brown, S.; Pyke, D.; Steenhof, P. Electric vehicles: The role and importance of standards in an emerging market. Energy Policy 2010, 38, 3797-3806. [CrossRef]

14. Zhao, H.; Li, N. Optimal siting of charging stations for electric vehicles based on fuzzy Delphi and hybrid multi-criteria decision making approaches from an extended sustainability perspective. Energies 2016, 9, 270. [CrossRef]

15. Frade, I.; Ribeiro, A.; Gonçalves, G.; Antunes, A.P. Optimal location of charging stations for electric vehicles in a neighborhood in Lisbon, Portugal. Transp. Res. Rec. 2011, 2252, 91-98. [CrossRef]

16. Barzani, S.P.; Ghahnavieh, R.A.; Karegar, K.H. Optimal fast charging station placing and sizing. Appl. Energy 2014, 125, 289-299. [CrossRef]

17. Hwang, C.L.; Yoon, K. Methods for multiple attribute decision making. In Multiple Attribute Decision Making; Springer: Berlin/Heidelberg, Germany, 1981; pp. 58-191.

18. Hwang, C.L.; Lai, Y.J.; Liu, T.Y. A new approach for multiple objective decision making. Comput. Oper. Res. 1993, 20 , 889-899. [CrossRef]

19. Tang, H.; Shi, Y.; Dong, P. Public blockchain evaluation using entropy and TOPSIS. Expert Syst. Appl. 2019, 117, 204-210. [CrossRef]

20. Sennaroglu, B.; Celebi, G.V. A military airport location selection by AHP integrated PROMETHEE and VIKOR methods. Transp. Res. Part D Transp. Environ. 2018, 59, 160-173. [CrossRef]

21. Gupta, P.; Mehlawat, M.K.; Grover, N. Intuitionistic fuzzy multi-attribute group decision-making with an application to plant location selection based on a new extended VIKOR method. Inf. Sci. 2016, 370, 184-203. [CrossRef]

22. Tian, Z.P.; Wang, J.Q.; Wang, J.; Zhang, H.Y. A multi-phase QFD-based hybrid fuzzy MCDM approach for performance evaluation: A case of smart bike-sharing programs in Changsha. J. Clean. Prod. 2018, 171, 1068-1083. [CrossRef]

23. Tian, Z.P.; Wang, J.Q.; Zhang, H.Y. An integrated approach for failure mode and effects analysis based on fuzzy best-worst, relative entropy, and VIKOR methods. Appl. Soft Comput. 2018, 72, 636-646. [CrossRef]

24. Zhao, H.; Guo, S. Selecting green supplier of thermal power equipment by using a hybrid MCDM method for sustainability. Sustainability 2014, 6, 217-235. [CrossRef]

25. Zadeh, L.A. Fuzzy sets. In Fuzzy Sets, Fuzzy Logic, and Fuzzy Systems: Selected Papers by LotfiAZadeh; World Scientific: Hackensack, NJ, USA, 1996; pp. 394-432.

26. Tang, Z.; Guo, C.; Hou, P.; Fan, Y. Optimal siting of electric vehicle charging stations based on voronoi diagram and fahp method. Energy Power Eng. 2013, 5, 1404-1409. [CrossRef]

27. Feizizadeh, B.; Roodposhti, M.S.; Jankowski, P.; Blaschke, T. A GIS-based extended fuzzy multi-criteria evaluation for landslide susceptibility mapping. Comput. Geosci. 2014, 73, 208-221. [CrossRef]

28. Lee, W.; Xiang, L.; Schober, R.; Wong, V.W. Electric vehicle charging stations with renewable power generators: A game theoretical analysis. IEEE Trans. Smart Grid 2014, 6, 608-617. [CrossRef]

29. Rivera, S.; Wu, B.; Kouro, S.; Yaramasu, V.; Wang, J. Electric vehicle charging station using a neutral point clamped converter with bipolar DC bus. IEEE Trans. Ind. Electron. 2014, 62, 1999-2009. [CrossRef]

30. Wang, Q.; Zhou, N.; Wang, J.; Wei, N. Harmonic amplification investigation and calculation of electric vehicle charging stations using three-phase uncontrolled rectification chargers. Electr. Power Syst. Res. 2015, 123, 174-184. [CrossRef]

31. Ding, H.; Hu, Z.; Song, Y. Value of the energy storage system in an electric bus fast charging station. Appl. Energy 2015, 157, 630-639. [CrossRef]

32. Fan, P.; Sainbayar, B.; Ren, S. Operation analysis of fast charging stations with energy demand control of electric vehicles. IEEE Trans. Smart Grid 2015, 6, 1819-1826. [CrossRef]

33. Capasso, C.; Veneri, O. Experimental study of a DC charging station for full electric and plug in hybrid vehicles. Appl. Energy 2015, 152, 131-142. [CrossRef]

34. Li, S.; Bao, K.; Fu, X.; Zheng, H. Energy management and control of electric vehicle charging stations. Electr. Power Compon. Syst. 2014, 42, 339-347. [CrossRef]

35. Nansai, K.; Tohno, S.; Kono, M.; Kasahara, M.; Moriguchi, Y. Life-cycle analysis of charging infrastructure for electric vehicles. Appl. Energy 2001, 70, 251-265. [CrossRef]

36. Khalkhali, K.; Abapour, S.; Tafreshi, M.S.M.; Abapour, M. Application of data envelopment analysis theorem in plug-in hybrid electric vehicle charging station planning. IET Gener. Transm. Distrib. 2015, 9, 666-676. [CrossRef]

37. Liu, J. Electric vehicle charging infrastructure assignment and power grid impacts assessment in Beijing. Energy Policy 2012, 51, 544-557. [CrossRef]

38. Wirges, J.; Linder, S.; Kessler, A. Modelling the development of a regional charging infrastructure for electric vehicles in time and space. Eur. J. Transp. Infrastruct. Res. 2012, 12. [CrossRef]

39. Wang, Z.; Liu, P.; Cui, J.; Xi, Y.; Zhang, L. Research on quantitative models of electric vehicle charging stations based on principle of energy equivalence. Math. Probl. Eng. 2013, 2013. [CrossRef]

40. He, F.; Wu, D.; Yin, Y.; Guan, Y. Optimal deployment of public charging stations for plug-in hybrid electric vehicles. Transp. Res. Part B Methodol. 2013, 47, 87-101. [CrossRef] 
41. Liu, Z.; Wen, F.; Ledwich, G. Optimal planning of electric-vehicle charging stations in distribution systems. IEEE Trans. Power Deliv. 2012, 28, 102-110. [CrossRef]

42. Pashajavid, E.; Golkar, M.A. Optimal placement and sizing of plug in electric vehicles charging stations within distribution networks with high penetration of photovoltaic panels. J. Renew. Sustain. Energy 2013, 5, 3126. [CrossRef]

43. Chen, T.D.; Kockelman, K.M.; Khan, M. Locating electric vehicle charging stations: Parking-based assignment method for Seattle, Washington. Transp. Res. Rec. 2013, 2385, 28-36. [CrossRef]

44. Sathaye, N.; Kelley, S. An approach for the optimal planning of electric vehicle infrastructure for highway corridors. Transp. Res. Part E Logist. Transp. Rev. 2013, 59, 15-33. [CrossRef]

45. Wang, G.; Xu, Z.; Wen, F.; Wong, K.P. Traffic-constrained multiobjective planning of electric-vehicle charging stations. IEEE Trans. Power Deliv. 2013, 28, 2363-2372. [CrossRef]

46. Dong, J.; Liu, C.; Lin, Z. Charging infrastructure planning for promoting battery electric vehicles: An activity-based approach using multiday travel data. Transp. Res. Part C Emerg. Technol. 2014, 38, 44-55. [CrossRef]

47. Xu, H.; Miao, S.; Zhang, C.; Shi, D. Optimal placement of charging infrastructures for large-scale integration of pure electric vehicles into grid. Int. J. Electr. Power Energy Syst. 2013, 53, 159-165. [CrossRef]

48. You, P.S.; Hsieh, Y.C. A hybrid heuristic approach to the problem of the location of vehicle charging stations. Comput. Ind. Eng. 2014, 70, 195-204. [CrossRef]

49. Lee, Y.G.; Kim, H.S.; Kho, S.Y.; Lee, C. User Equilibrium-Based Location Model of Rapid Charging Stations for Electric Vehicles with Batteries That Have Different States of Charge. Transp. Res. Rec. 2014, 2454, 97-106. [CrossRef]

50. Baouche, F.; Billot, R.; Trigui, R.; El Faouzi, N.E. Efficient allocation of electric vehicles charging stations: Optimization model and application to a dense urban network. IEEE Intell. Transp. Syst. Mag. 2014, 6, 33-43. [CrossRef]

51. Yao, W.; Zhao, J.; Wen, F.; Dong, Z.; Xue, Y.; Xu, Y.; Meng, K. A multi-objective collaborative planning strategy for integrated power distribution and electric vehicle charging systems. IEEE Trans. Power Syst. 2014, 29, 1811-1821. [CrossRef]

52. Ma, T.; Zhao, J.; Xiang, S.; Zhu, Y.; Liu, P. An agent-based training system for optimizing the layout of AFVs' initial filling stations. J. Artif. Soc. Soc. Simul. 2014, 17, 6. [CrossRef]

53. Chung, S.H.; Kwon, C. Multi-period planning for electric car charging station locations: A case of Korean Expressways. Eur. J. Oper. Res. 2015, 242, 677-687. [CrossRef]

54. Lam, A.Y.; Leung, Y.W.; Chu, X. Electric vehicle charging station placement: Formulation, complexity, and solutions. IEEE Trans. Smart Grid 2014, 5, 2846-2856. [CrossRef]

55. Cai, H.; Jia, X.; Chiu, A.S.; Hu, X.; Xu, M. Siting public electric vehicle charging stations in Beijing using big-data informed travel patterns of the taxi fleet. Transp. Res. Part D Transp. Environ. 2014, 33, 39-46. [CrossRef]

56. Önüt, S.; Soner, S. Transshipment site selection using the AHP and TOPSIS approaches under fuzzy environment. Waste Manag. 2008, 28, 1552-1559. [CrossRef]

57. Ghorui, N.; Ghosh, A.; Algehyne, E.A.; Mondal, S.P.; Saha, A.K. AHP-TOPSIS Inspired Shopping Mall Site Selection Problem with Fuzzy Data. Mathematics 2020, 8, 1380. [CrossRef]

58. Mohajeri, N.; Amin, G.R. Railway station site selection using analytical hierarchy process and data envelopment analysis. Comput. Ind. Eng. 2010, 59, 107-114. [CrossRef]

59. Liu, H.C.; You, J.X.; Fan, X.J.; Chen, Y.Z. Site selection in waste management by the VIKOR method using linguistic assessment. Appl. Soft Comput. 2014, 21, 453-461. [CrossRef]

60. Jun, D.; Tian, T.F.; Sheng, Y.Y.; Yu, M. Macro-site selection of wind/solar hybrid power station based on ELECTRE-II. Renew. Sustain. Energy Rev. 2014, 35, 194-204. [CrossRef]

61. Malczewski, J. GIS-based multicriteria decision analysis: A survey of the literature. Int. J. Geogr. Inf. Sci. 2006, 20, 703-726. [CrossRef]

62. Özceylan, E.; Erbaş, M.; Tolon, M.; Kabak, M.; Durğut, T. Evaluation of freight villages: A GIS-based multi-criteria decision analysis. Comput. Ind. 2016, 76, 38-52. [CrossRef]

63. Atici, K.B.; Simsek, A.B.; Ulucan, A.; Tosun, M.U. A GIS-based Multiple Criteria Decision Analysis approach for wind power plant site selection. Util. Policy 2015, 37, 86-96. [CrossRef]

64. Çetinkaya, C.; Özceylan, E.; Erbaş, M.; Kabak, M. GIS-based fuzzy MCDA approach for siting refugee camp: A case study for southeastern Turkey. Int. J. Disaster Risk Reduct. 2016, 18, 218-231. [CrossRef]

65. Garg, H. A new generalized improved score function of interval-valued intuitionistic fuzzy sets and applications in expert systems. Appl. Soft Comput. 2016, 38, 988-999. [CrossRef]

66. Kumar, K.; Garg, H. TOPSIS method based on the connection number of set pair analysis under interval-valued intuitionistic fuzzy set environment. Comput. Appl. Math. 2018, 37, 1319-1329. [CrossRef]

67. Maity, S.; Chakraborty, A.; De, S.K.; Mondal, S.P.; Alam, S. A comprehensive study of a backlogging EOQ model with nonlinear heptagonal dense fuzzy environment. RAIRO Oper. Res. 2020, 54. [CrossRef]

68. Soni, H.; Sarkar, B.; Josh, M. Demand uncertainty and learning in fuzziness in a continuous review inventory model. J. Intell. FuzzySyst. 2017, 33, 2595-2608. [CrossRef]

69. Sarkar, B.; Mahapatra, A.S. Periodic review fuzzy inventory models with variable lead time and fuzzy demand. Int. Trans. Oper. Res. 2017, 24, 1197-1227. [CrossRef] 
70. Rahaman, M.; Mondal, S.P.; Shaikh, A.A.; Ahmadian, A.; Norazak, S.; Salahshour, S. Arbitrary-order economic production quantity model with and without deterioration: Generalized point of view. Adv. Differ. Equ. 2020, 16, 1-30. [CrossRef]

71. Rahaman, M.; Mondal, S.P.; Alam, S.; Khan, N.A.; Biswas, A. Interpretation of exact solution for fuzzy fractional non-homogeneous differential equation under the Riemann-Liouville sense and its application on the inventory management control problem. Granul. Comput. 2020, 1-24. [CrossRef]

72. Rahaman, M.; Mondal, S.P.; Shaikh, A.; Pramanik, A.P.; Roy, S.; Maity, M.K.; Mondal, R.; De, D. Artificial bee colony optimizationinspired synergetic study of fractional-order economic production quantity model. Soft Comput. 2020, 24, 15341-15359. [CrossRef]

73. Chakraborty, A.; Maity, S.; Jain, S.; Mondal, S.P.; Alam, S. Hexagonal fuzzy number and its distinctive representation, ranking, defuzzification technique and application in production inventory management problem. Granul. Comput. 2020, 1-15. [CrossRef]

74. Buckley, J.J. Fuzzy Hierarchical Analysis. In Fuzzy Sets Systems; World Scientific: Hackensack, NJ, USA, 1985.

75. Satty, T.L. The Analytic Hierarchy Process; McGraw-Hill: New York, NY, USA, 1980.

76. Yoon, K.P.; Hwang, C.L. Multiple Attribute Decision Making: An Introduction; Sage Publications: Thousand Oaks, CA, USA, 1995.

77. Sodhi, B.; Prabhakar, T.V. A simplified description of Fuzzy TOPSIS. arXiv 2012, arXiv:1205.5098. Available online: https: / / arxiv.org/abs/1205.5098 (accessed on 15 February 2021).

78. Zavadskas, E.K.; Kaklauskas, A.; Sarka, V. The new method of multicriteria complex proportional assessment of projects. Technol. Econ. Dev. Econ. 1994, 1, 131-139.

79. Ghose, D.; Pradhan, S.; Tamuli, P.; Shabbiruddin. Optimal material for solar electric vehicle application using an integrated Fuzzy-COPRAS model. Energy Sources Part A Recovery Util. Environ. Eff. 2019, 1-20. [CrossRef]

80. Tolga, A.C.; Durak, G. Evaluating Innovation Projects in Air Cargo Sector with Fuzzy COPRAS. In International Conference on Intelligent and Fuzzy Systems; Springer: Cham, Switzerland, 2019; pp. 702-710.

81. Yao, R.; Bai, H.; Xu, H. Where should China's thermal power industry prioritize its B\&R investment? A study based on an environmental site selection analysis. J. Clean. Prod. 2019, 215, 669-679.

82. Modrak, V.; Soltysova, Z. Development of operational complexity measure for selection of optimal layout design alternative. Int. J. Prod. Res. 2018, 56, 7280-7295. [CrossRef]

83. Manerba, D.; Mansini, R.; Perboli, G. The capacitated supplier selection problem with total quantity discount policy and activation costs under uncertainty. Int. J. Prod. Econ. 2018, 198, 119-132. [CrossRef]

84. Kınay, Ö.B.; da Gama, S.F.; Kara, B.Y. On multi-criteria chance-constrained capacitated single-source discrete facility location problems. Omega 2019, 83, 107-122. [CrossRef]

85. Hosseini, S.; Sarder, M.D. Development of a Bayesian network model for optimal site selection of electric vehicle charging station. Int. J. Electr. Power Energy Syst. 2019, 105, 110-122. [CrossRef]

86. Zha, Y.; Gao, J.; Ni, S. Use of normalized difference built-up index in automatically mapping urban areas from TM imagery. Int. J. Remote Sens. 2003, 24, 583-594. [CrossRef] 